\title{
The meteorology and chemistry of high nitrogen oxide concentrations in the stable boundary layer at the South Pole
}

\author{
William Neff $^{1}$, Jim Crawford ${ }^{2}$, Marty Buhr ${ }^{3}$, John Nicovich ${ }^{4}$, Gao Chen ${ }^{2}$, and Douglas Davis ${ }^{4, \dagger}$ \\ ${ }^{1}$ NOAA/ESRL Physical Sciences Division and University of Colorado, Cooperative Institute for Research in \\ Environmental Sciences, Boulder CO 80305, USA \\ ${ }^{2}$ NASA Langley Research Center, Hampton, VA 23681, USA \\ ${ }^{3}$ Air Quality Design, Golden, CO 80403, USA \\ ${ }^{4}$ School of Earth and Atmospheric Science, Georgia Institute of Technology, Atlanta, GA 30332, USA \\ $\dagger$ deceased
}

Correspondence: William Neff (william.neff@noaa.gov)

Received: 30 August 2017 - Discussion started: 11 September 2017

Revised: 28 January 2018 - Accepted: 30 January 2018 - Published: 14 March 2018

\begin{abstract}
Four summer seasons of nitrogen oxide (NO) concentrations were obtained at the South Pole (SP) during the Sulfur Chemistry in the Antarctic Troposphere (ISCAT) program (1998 and 2000) and the Antarctic Tropospheric Chemistry Investigation (ANTCI) in (2003, 2005, 2006-2007). Together, analyses of the data collected from these studies provide insight into the large- to small-scale meteorology that sets the stage for extremes in NO and the significant variability that occurs day to day, within seasons, and year to year. In addition, these observations reveal the interplay between physical and chemical processes at work in the stable boundary layer of the high Antarctic plateau. We found a systematic evolution of the large-scale wind system over the ice sheet from winter to summer that controls the surface boundary layer and its effect on NO: initially in early spring (Days 280-310) the transport of warm air and clouds over West Antarctica dominates the environment over the SP; in late spring (Days 310-340), the winds at $300 \mathrm{hPa}$ exhibit a bimodal behavior alternating between northwest and southeast quadrants, which is of significance to NO; in early summer (Days 340-375), the flow aloft is dominated by winds from the Weddell Sea; and finally, during late spring, winds aloft from the southeast are strongly associated with clear skies, shallow stable boundary layers, and light surface winds from the east - it is under these conditions that the highest NO occurs. Examination of the winds at $300 \mathrm{hPa}$ from 1961 to 2013 shows that this seasonal pattern has not changed significantly, although the last twenty years have seen an increasing trend
\end{abstract}

in easterly surface winds at the SP. What has also changed is the persistence of the ozone hole, often into early summer. With lower total ozone column density and higher sun elevation, the highest actinic flux responsible for the photolysis of snow nitrate now occurs in late spring under the shallow boundary layer conditions optimum for high accumulation of $\mathrm{NO}$. This may occur via the non-linear $\mathrm{HO}_{X}-\mathrm{NO}_{x}$ chemistry proposed after the first ISCAT field programs and $\mathrm{NO}_{x}$ recycling to the surface where quantum yields may be large under the low-snow-accumulation regime of the Antarctic plateau. During the 2003 field program a sodar made direct measurements of the stable boundary layer depth (BLD), a key factor in explaining the chemistry of the high NO concentrations. Because direct measurements were not available in the other years, we developed an estimator for BLD using direct observations obtained in 2003 and step-wise linear regression with meteorological data from a $22 \mathrm{~m}$ tower (that was tested against independent data obtained in 1993). These data were then used with assumptions about the column abundance of NO to estimate surface fluxes of $\mathrm{NO}_{x}$. These results agreed in magnitude with results at Concordia Station and confirmed significant daily, intraseasonal and interannual variability in NO and its flux from the snow surface. Finally, we found that synoptic to mesoscale eddies governed the boundary layer circulation and accumulation pathways for $\mathrm{NO}$ at the SP rather than katabatic forcing. It was the small-scale features of the circulation including the transition from cloudy to clear conditions that set the stage for short-term extremes 
in NO, whereas larger-scale features were associated with more moderate concentrations.

\section{Introduction}

The Investigation of Sulfur Chemistry in the Antarctic Troposphere (ISCAT) field programs, in the austral summers of 1998 and 2000 (Davis et al., 2004a, 2001), discovered unexpectedly high atmospheric nitrogen oxide (NO) concentrations at the South Pole (SP). These early investigations suggested that the high NO levels were associated with continuous sunlight, shallow stable boundary layers, downslope flow from the east Antarctic plateau, and associated non-linear $\mathrm{NO}_{x}-\mathrm{HO}_{X}$ chemistry that resulted in long $\mathrm{NO}_{x}$ lifetimes (Davis et al., 2004b, 2008). It was also argued that the high levels of NO at the SP, compared to other polar sites, were partly due to the long fetches for air parcels in the katabatic flow from the Antarctic high plateau and the lack of a diurnal cycle, thus allowing continuous photolysis of snow nitrate. A major field program followed in 2003 to re-examine this phenomenon, the Antarctic Tropospheric Chemistry Investigation (ANTCI; Eisele et al., 2008). This new study involved ground-based measurements at SP as well as aircraft probing over more extensive areas of the Antarctic Plateau in 2003 (Davis et al., 2008) and then again in 2005 (Slusher et al., 2010). These field studies reinforced the earlier ISCAT results and introduced evidence suggesting that fast recycling mechanisms for redeposited nitrate could be important given that photolysis of buried nitrate appeared inadequate to explain the sustained levels of atmospheric $\mathrm{NO}_{x}$. In combination with meteorological factors, this recycling enabled $\mathrm{NO}_{x}$ levels which routinely reached and/or exceeded several hundred pptv. Because of significant daily, seasonal, and interannual variability in NO observed in the previous field studies this paper will examine in greater detail the influence of large- to small-scale meteorological circulations on the boundary layer and associated chemical factors that set the stage for high NO episodes. A key feature of the boundary layer at the SP is that it is statically stable throughout most of the year and often very shallow. This leads to the confinement of surface chemical emissions near the surface except during higher-wind events and cloudy periods when a deeper internally well-mixed inversion layer is often present. Important factors also influencing the near-surface chemical environment include the following: the winter-to-summer seasonal cycle in wind and temperature as well as inter-annual variability and synoptic variability in cloudiness (important to the surface energy budget and the boundary layer structure); low snow accumulation; and total column ozone and the radiative changes associated with the breakup of the stratospheric polar vortex and ozone hole in the spring. Past work (Neff, 1999) found evidence for the effect of stratospheric ozone depletion on the tropospheric circulation in the austral spring over the interior of Antarctica. A key question then was the potentially combined effects of changes in the radiative environment (via UV photolysis) and concomitant changes in the near-surface meteorology affecting NO. The complexity of the potential processes affecting NO are well captured graphically in Davis et al. (2008, their Fig. 2) where they identify atmosphere-surface exchange processes, plateau drainage, loss mechanisms associated with continental outflow, lower latitude transport into the continent, and boundary layer-free troposphere exchange as key meteorological processes. However, earlier work did not examine year-to-year meteorological variability and effects on NO. In addition, the step-wise linear regression that we show later demonstrates that the dominant parameters for NO vary from year to year reflecting the variability in weather regimes affecting NO at the SP. Thus, the new finding we will show is that not only are many variables important, but also that the relative importance of specific variables varies from year to year.

To address some of these processes, we analyze previous data sets complemented by a new data set collected in 2006 2007 that extends over much of the seasonal cycle. Past work emphasized the relationship between high NO and shallow boundary layers (Davis et al., 2008; Neff et al., 2008). Here, the primary focus is on providing a broader perspective of the origin and evolution of high NO episodes, their relationship to stable boundary layer meteorology, the unique large-scale meteorology of the high Antarctic plateau, the influence of the changes in the stratosphere in recent decades, and the effect of variability within seasons as well as from year to year.

\section{NO, the seasonal cycle, and boundary layer meteorology}

In this section, we examine the meteorological factors controlling boundary layer depth (BLD) and NO variability, over hourly, intraseasonal, and interannual timescales, using the summer field program data from 1998, 2000, 2003, and 2006 to 2007. Because NO was the one species measured consistently in all field studies cited, it will be used in most of the follow-on discussions ( $\mathrm{NO}$ and $\mathrm{NO}_{2}$ were both measured in 2006-2007). This analysis benefits from a repeatable weather cycle at SP and the lack of a diurnal solar insolation cycle. The weather cycle typically includes a period of advection of warm air, higher wind speeds, and clouds with a deep boundary layer followed by clearing skies, strong radiative surface cooling, and formation of shallow statically stable boundary layers (Neff, 1999). These changes occur over normal synoptic timescales of a few days and over planetary wave timescales of 10-60 days (Yasunari and Kodama, 1993). During periods of warm air advection and cloudy conditions, the surface inversion can be fairly deep and well mixed as the warm air adjusts to a colder ice surface. In these cases the boundary layer is often several hundred me- 
ters deep (Neff, 1980). This is in contrast to clear sky conditions: a unique aspect of the SP includes a high snow albedo and low sun elevation angle $\left(\sim 23.5^{\circ}\right.$ at solstice $)$. Because of this combination the surface typically suffers a net loss of energy under clear sky conditions (Stone and Kahl, 1991) even at the summer solstice. This effect is in contrast with summer observations at Concordia Station $\left(\sim 75^{\circ} \mathrm{S}, 3233\right.$ ma.s.l.: diurnal solar elevation at solstice $8.5^{\circ}$ to $\left.38.5^{\circ}\right)$ and Dome Argus $\left(\sim 80^{\circ} \mathrm{S}, 4093\right.$ ma.s.l.: diurnal solar elevation at solstice $13.5^{\circ}$ to 33.8 ), which show a diurnal cycle of thermal convection followed by the formation of a stable boundary layer during the "evening (low sun elevation)" period (Frey et al., 2015) (Bonner, 2015; Bonner et al., 2010). A detailed study of the surface energy budget and boundary layer evolution at Concordia Station (King et al., 2006) shows a convective boundary layer and positive net radiation lasting eight hours (averaged over December and January). This convective period developed when the solar elevation angle was greater than $25^{\circ}$, in contrast to the lack of thermal convection at the SP where the maximum solar elevation angle is always less than this. Frey et al. (2015) show a specific example for 9 January at Concordia when a stable boundary layer forms with large increases in NO shortly after 18:00 LT when the solar elevation angle decreases to less than $20^{\circ}$. Similarly King et al. (2006) show a sodar record from 28 January with a stable boundary layer until 08:00 and after 17:30 LT when solar elevation angle less than $\sim 22^{\circ}$. For these reasons air masses arriving over long distances at the SP are likely to have encountered some convective mixing enroute and may need to be considered in future model simulations of surface chemistry.

\subsection{Overview of the four field seasons}

The first three field seasons have been described in some detail (Davis et al., 2001, 2004b, 2008), whereas a fourth more extensive observation of the seasonal cycle in NO, obtained in 2006-2007, has not yet been published. The four seasons of NO data are shown in Fig. 1 and their statistics in Table 1. In 1998, the ozone hole broke up very late as seen in Fig. 1a but the observational program was also delayed until early December. In 2000 (Fig. 1b), total column ozone increased well before the beginning of the field season and NO remained relatively low. In both 2003 (Fig. 1c) and 2006, the ozone hole broke up about the same time but higher column ozone was more persistent in 2006 until late December. In Fig. 1d for 2006, we also show the solar elevation angle increasing $(\times 30)$ from $14.5^{\circ}$ to $23.5^{\circ}$ as well as the nitrate photolysis rate $j\left(\mathrm{NO}_{3}^{-}\right)$which initially follows the seasonal increase in elevation angle but responds after Julian Day (JD) 330 to shorter-term variations in total column ozone and meteorology. In both 2003 and 2006, prolonged periods of high NO concentrations occur prior to JD 340. In particular, in 2003, the period of JD 326-336 has a median concentration of 482 pptv, whereas the sustained period in 2006 (JD 322-
Table 1. Percentage of hourly NO values in three ranges compared over the four experiment years shown in Fig. 1.

\begin{tabular}{lrrrr}
\hline & 1998 & 2000 & 2003 & 2006 \\
\hline Total hours & 438 & 806 & 516 & 1601 \\
NO $<200$ pptv & $28 \%$ & $89 \%$ & $31 \%$ & $68 \%$ \\
200 pptv $<$ NO $<500$ pptv & $68 \%$ & $10 \%$ & $44 \%$ & $29 \%$ \\
NO $>500$ pptv & $4 \%$ & $1 \%$ & $25 \%$ & $3 \%$ \\
\hline
\end{tabular}

331) has a median value of $389 \mathrm{pptv}, \sim 25 \%$ lower than in 2003. After JD 340 the median values are $247,91,152$, and $146 \mathrm{pptv}$ for each of the four seasons respectively. Higher NO values in 1998, after JD 340, presumably reflect the delay in the breakup of the ozone hole. In Table 1, we summarize the occurrence of $\mathrm{NO}$ concentrations in three ranges for each of the field seasons. 2003 stands out as having the highest number of NO concentrations exceeding 500 pptv, $90 \%$ of which occurred before JD 335 while 2000 had the fewest. 1998 also saw the fewest hours of NO exceeding 500 pptv. From the perspective of Fig. 1, the first three years produced diverse results. The additional data in 2006 , while more extensive, confirmed the general seasonal pattern seen in 2003 with the most persistent high NO occurring in November.

\subsection{The seasonal cycle, upper-level winds and their influence on surface flows}

As the stratosphere over Antarctica begins warming around the time of the spring equinox, prevailing winds at the height of the summer tropopause over the SP $(\sim 300 \mathrm{hPa})$ evolve in three stages as shown in Fig. 2 (based on rawinsonde data for the period 1990 to 2013). In Fig. S1 in the Supplement we provide more detailed wind-rose plots for each subseason as well as cloud fraction as a function of $300 \mathrm{hPa}$ wind direction for extremes in daily cloud fraction of $8-10$ tenths and 0 2 tenths.

In early spring (JD 280-310), $300 \mathrm{hPa}$ winds are largely from the direction of West Antarctica and associated with high cloud fraction and advection of warmer air at the SP (Neff, 1999). This period coincides with the maximum in the semi-annual oscillation when the circumpolar trough is most intense (Meehl, 1991). Although there can be significant year-to-year variability in storminess, October can be the period of greatest snow accumulation (as measured in the stake field at the SP). The average accumulation in October from 1990 to 2015 is $3 \mathrm{~cm}$, whereas in November it is $1.5 \mathrm{~cm}$ (ftp://amrc.ssec.wisc.edu/pub/southpole/climatology/). During that 25 year period, 2003 was one of the four highest accumulation years. In 2003, the snow depth increased by $6 \mathrm{~cm}$ in October, whereas in November it decreased by $1 \mathrm{~cm}$. In our other experiment years the accumulation ranged from $1.5 \mathrm{~cm}$ (2006) to $4.0 \mathrm{~cm}$ (2000) in November. The accumulation rate may be important to the fate of nitrate in the snow (e.g., Mulvaney et al., 1998) as well as the exposure of ni- 

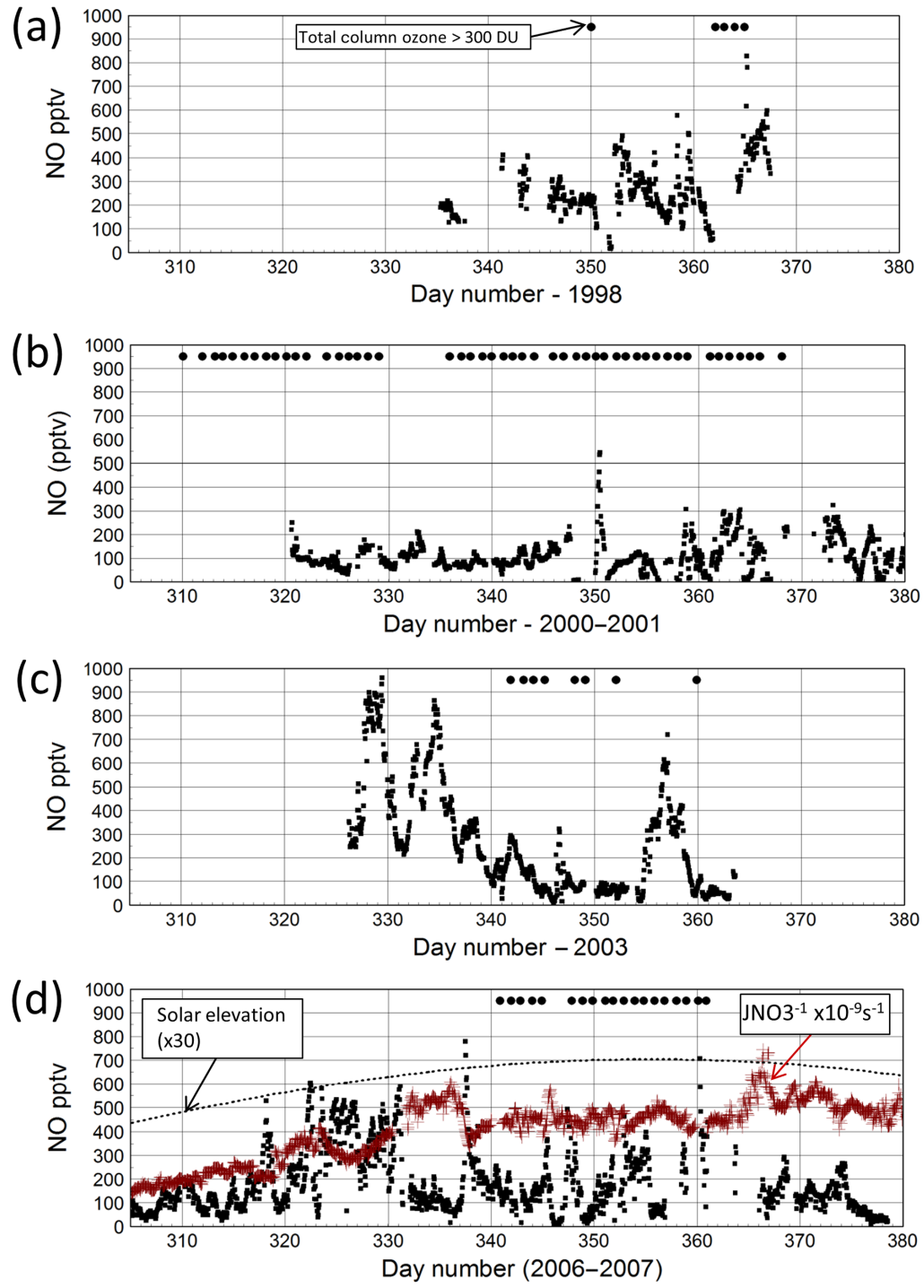

Figure 1. Periods of data collection used in our analysis for (a) 1998, (b) 2000-2001, (c) 2003, and (d) 2006-2007. Periods of daily total column ozone in excess of 300 DU appear at the top of each panel. In (d) the seasonal change in solar elevation angle (x30) is shown together with the nitrate photolysis rate $\left(\mathrm{NO}_{3}^{-1}\right)$.

trate in the skin layer to photolysis and recycling (e.g., Frey et al., 2015). As the season evolves during the late spring (JD 310-340), the winds become semi-bimodal as shown in Fig. 2 where percentages in $45^{\circ}$ bins have peaks centered almost $180^{\circ}$ apart at south-southeast and northwest. The most significant aspect of this semi-bimodal distribution is the much diminished transport of warm air from West Antarctica and lower cloud fraction at SP. As reported in Neff (1999), this late spring period also has the lowest average cloudiness (see also Fig. S8 for more recent data). Furthermore, for winds greater than $10 \mathrm{~m} \mathrm{~s}^{-1}$ at $300 \mathrm{hPa}$, between 1990 and 2010 , in the $45^{\circ}$ intervals centered on south-southeast and northwest, the average surface inversion strength (from rawinsonde soundings) and surface wind speed are $6.3^{\circ} \mathrm{C}$ and $3.5 \mathrm{~m} \mathrm{~s}^{-1}$ and $2.5^{\circ} \mathrm{C}$ and $5.4 \mathrm{~m} \mathrm{~s}^{-1}$, respectively. Thus, in addition to reduced cloudiness during this period, surface wind speeds are less and surface-based inversion strengths are larger for $300 \mathrm{hPa}$ winds from the southeast. As seen in Fig. S1, clear sky conditions are most likely with winds aloft from east-southeast to southeast. In early summer, the occurrence of south-southeast winds decrease while the frequency of winds from the north-northwest increases. (For the early summer period, the surface inversion strength and wind speed results are similar at $2.2{ }^{\circ} \mathrm{C}$ and $3.1 \mathrm{~m} \mathrm{~s}^{-1}$ and $0.3{ }^{\circ} \mathrm{C}$ and $5.9 \mathrm{~m} \mathrm{~s}^{-1}$, respectively).

The difference in surface wind speed and inversion strength for the northwest and southeast modes can be explained in terms of the $300 \mathrm{hPa}$ geopotential height (GPH) 
(a)

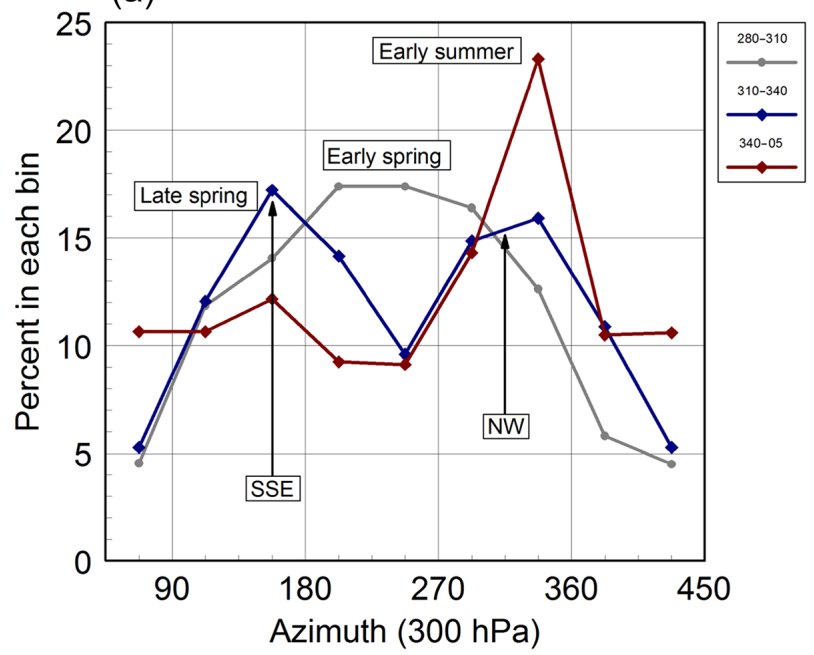

(b)

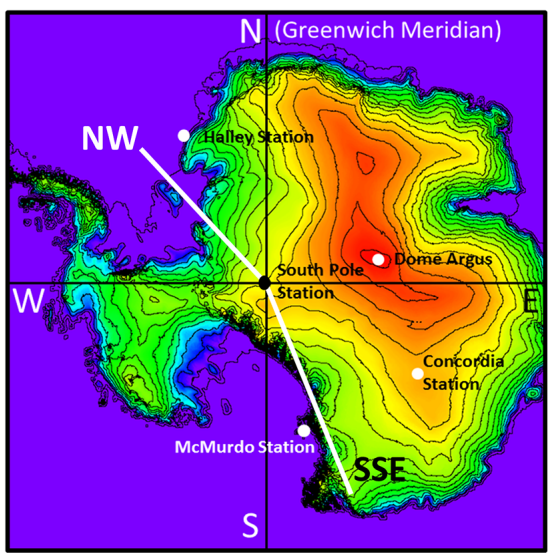

Figure 2. (a) Histograms of wind directions sorted in $45^{\circ}$ bins $\left(>5 \mathrm{~m} \mathrm{~s}^{-1}\right)$ at $300 \mathrm{hPa}$ for early spring (Days 280-310, gray line), late spring (Days 310-340, blue line), and early summer (Days 340-370, red line) over the period 1990-2013 (For more detail see Fig. S1). (b) Topographic map of Antarctica. In late winter/early spring winds aloft are primarily from the direction of West Antarctica and the Amundsen Sea (south to northwest). In late spring, $300 \mathrm{hPa}$ winds become semi-bimodal in direction, with higher probabilities from southsoutheast and northwest and fewer from the west-southwest. Past work has indicated that winds from the southeast quadrant bring cooler temperatures and lighter wind speeds to the SP: this direction corresponds to an inland directed synoptic-scale pressure gradient. Conversely, $300 \mathrm{hPa}$ winds centered on the northwest quadrant are typically associated with higher surface winds, increased cloudiness, and warmer temperatures: this direction reflects an off-shore directed synoptic pressure gradient. In early summer, winds at $300 \mathrm{hPa}$ increasingly favor a north-northwest direction from the Weddell Sea.

patterns corresponding to the two modes of upper-level winds (Fig. S2). For northwest winds, low GPH lies between the Ross and Weddell seas over West Antarctica with higher GPH over the continental interior. For southeast winds, lower GPH lies in the Eastern Hemisphere extending over most of the high plateau. Although somewhat different than the winter pattern in Neff (1999) where for southeast winds aloft a strong ridge of high pressure extended from the Ross Sea over portions of East Antarctica, the large-scale pressure gradient force still reveals either an on-shore or off-shore orientation in the two cases. In the case with low pressure centered mostly over high terrain, downslope flows would likely be weaker, whereas the inverse would be true for off-shore pressure gradient forces.

Figure 3 shows the year-to-year variability in the occurrence of southeast winds for the more recent period 19902013. where the year 2002 has been eliminated as it was the year of the only sudden stratospheric warming observed over Antarctica and may have subsequently affected the tropospheric circulation (Charlton et al., 2005). Figure 3 shows the semi-decadal variability documented previously for the period 1961-1998 (Neff, 1999). For each of the four observational periods (approximately mid-November through December for consistency) the frequencies of occurrence of winds at $300 \mathrm{hPa}$ from the southeast were as follows: $27 \%$ in $1998,2 \%$ in 2000, $24 \%$ in 2003, and $42 \%$ in 2006. For each of these periods when NO was recorded at SP, the number

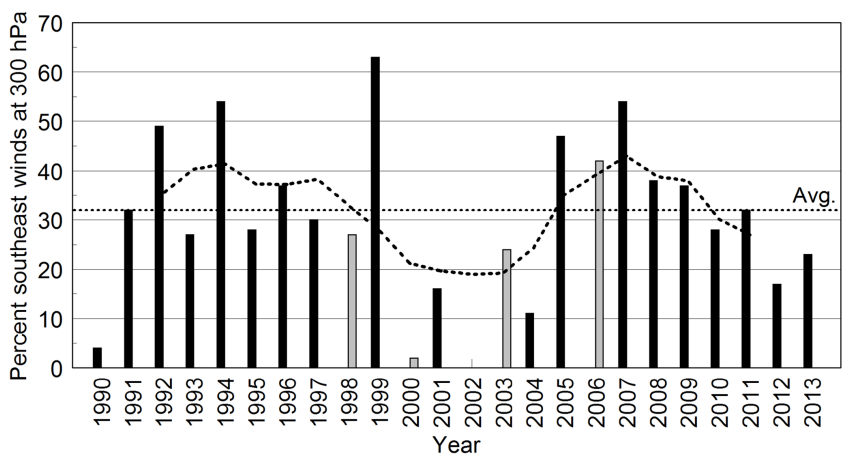

Figure 3. Percent of $300 \mathrm{hPa}$ wind directions between $67.5^{\circ}$ and $202.5^{\circ}$ (southeast) for each year 1990-2013 for mid-November through December. Experiment years are shaded gray and the longer-term variability shown using a 5-year smoothing. The year 2002 was eliminated because of the never-before-seen sudden stratospheric warming which occurred that year and may have affected the tropospheric circulation (Charlton et al., 2005). The average over 20 years is shown by the dashed line.

of hours of $\mathrm{NO}>250$ pptv were as follows: $42 \%$ in 1998 , $4 \%$ in $2000,56 \%$ in 2003, and $29 \%$ in 2006. The lack of a one-to-one relationship between the occurrence of southeast winds and NO concentrations suggest additional year-toyear variability in chemical source terms, surface snow characteristics and the details of the synoptic weather conditions 
favorable to high NO. What does stand out in 2000 , with very low frequency of winds from the southeast quadrant is the limited number of hours when NO exceeded 250 pptv, thus indicating the seasonal dependence of $\mathrm{NO}$ concentrations on the large-scale weather patterns over the Antarctic.

Figure 4a shows the distribution of surface wind directions for each experiment year as well as the average NO for each year as a function of surface wind direction in Fig. 4b. Although the wind distributions are similar for both 2003 and 2006, the average NO is less in 2006 for surface wind directions greater than $90^{\circ}$. In Fig. $4 \mathrm{~b}$, highest NO occurs with surface winds with an easterly component (between 60 and $180^{\circ}$ ). In Fig. 4c (for 1961-2010) we show the wind distribution at $300 \mathrm{hPa}$ for surface winds between 60 and $180^{\circ}$ and the distribution of surface winds in particular when the wind at $300 \mathrm{hPa}$ is between 120 and $150^{\circ}$ showing a $34^{\circ}$ offset between wind-direction medians aloft and at the surface. The breadth of the distributions may be related to discrete sampling with once- or twice-a-day rawinsondes and surface observations. Figure S3 explores, in more detail, the relationship of winds aloft to surface wind behavior for average surface wind directions (60 to $180^{\circ}$ ) associated with average NO greater than 200 pptv for late spring (Days 310-340) and for the full period of rawinsonde data starting in 1961. Figure S3a reveals strong interannual variability in the occurrence of surface winds with an easterly component as well as an upward trend exceeding $10 \%$ beginning in the late 1990s. In this case, we are only looking at the period of late spring, whereas in Fig. 2, the data extended to the end of December. Figure S3b shows similar interannual variability in southeast winds at $300 \mathrm{hPa}$ as well as multi-decadal variability but no systematic trend. In Fig. S3c, we show that extremes in the frequency of occurrence of winds from the southeast at $300 \mathrm{hPa}$ correspond to extremes in the occurrence of surface winds from the southeast with $r^{2}=0.4$. Comparing Fig. S3 with Fig. 2 which spanned the period mid-November to the end of December, shows that easterly surface winds occurred primarily after mid-December in 1998: however, in that year, the ozone hole breakup was delayed until the end of December and hence optimum boundary layer conditions favorable for high NO occurred with still-high actinic flux as seen in Fig. 1 where the 1998 field study started later in the seasonal cycle.

The surface inversion strength also varies strongly with the season as shown in Fig. S4a where we have plotted the average inversion strength from 1961 to 1998 (Neff, 1999) as well as daily data for 2006 showing typical short-term variability. (The inversion strength was determined from the daily or twice-daily rawinsonde temperature profile, measuring the difference from the $2 \mathrm{~m}$ tower temperature to that at the first relative maximum in the rawinsonde profile.) Because of the common assumption that the winds over Antarctic are largely katabatic in nature, motivated mainly by wintertime observations in coastal areas, we also show in Fig. S4a the geostrophic wind equivalent of inversion strengths of
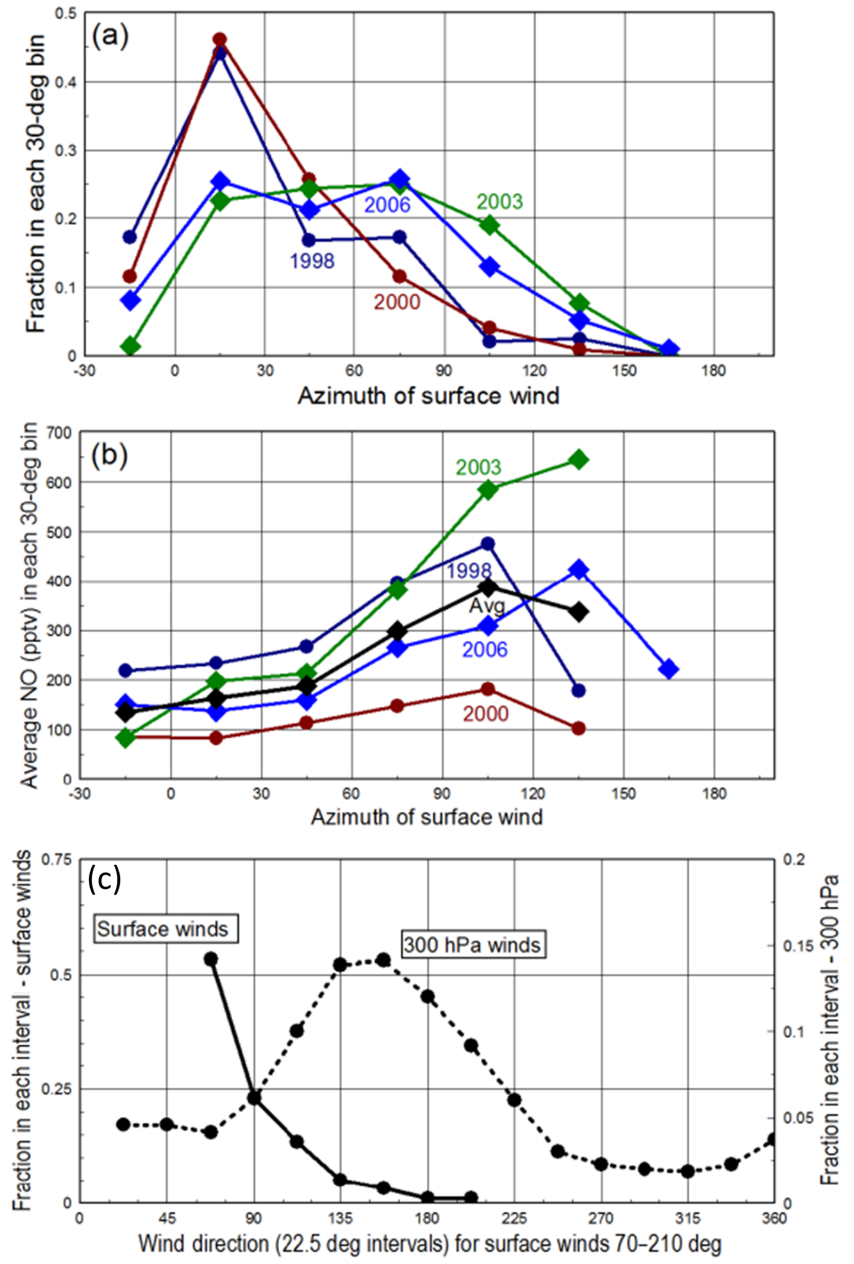

Figure 4. (a) Comparison of surface wind direction distributions for 1998, 2000, 2003, and 2006, (b) the average NO over each year as a function of wind azimuth in $30^{\circ}$ bins. Wind directions between $210^{\circ}$ and $340^{\circ}\left(-20^{\circ}\right)$ are not included because of potential contamination from the station and aircraft operations. A total of 3300 hourly values of $\mathrm{NO}$ were averaged in $30^{\circ}$ wind-direction bins. (c) Distribution of $300 \mathrm{hPa}$ wind directions when the surface wind is between $60^{\circ}$ and $180^{\circ}$ and greater than $1 \mathrm{~m} \mathrm{~s}^{-1}$. Also shown is the distribution of surface winds when the $300 \mathrm{hPa}$ wind directions are between 120 and $150^{\circ}$. Median values are 100 and $134^{\circ}$, respectively, showing that surface winds are more easterly when winds aloft are from the southeast.

$4^{\circ} \mathrm{C}\left(1 \mathrm{~m} \mathrm{~s}^{-1}\right)$ and $18^{\circ} \mathrm{C}\left(5 \mathrm{~m} \mathrm{~s}^{-1}\right)$ assuming a terrain slope of 0.001 , characteristic of the interior of the ice sheet and derived from (Ball, 1960) by Neff (1980). From Fig. S4a, geostrophic winds aloft of only $1 \mathrm{~m} \mathrm{~s}^{-1}$ will dominate over katabatic forcing from mid-December to mid-January. In Fig. S4b we show the distribution of wind speeds at $300 \mathrm{hPa}$ for December, averaged from 1998 to 2014. This figure shows that almost all synoptic-scale winds in December at $300 \mathrm{hPa}$ imply surface synoptic pressure gradients substantially greater than the katabatic ones associated with summer 
inversion strengths (Neff, 1980, 1999, Sect. 4.2; Parish and Cassano, 2003). The conclusion from the previous figures is that synoptic and mesoscale pressure gradients at the surface dominate over those driving katabatic flows over the interior of Antarctica, especially in the period November-January, and that $300 \mathrm{hPa}$ winds from the southeast provide a significant control over the boundary layer depth important to high NO. Past work has suggested that katabatic trajectories may have been responsible for long fetches over which NO could accumulate (Davis et al., 2004b). However, from these arguments it appears more likely that meso- to synoptic-scale circulations define accumulation pathways over the interior of Antarctica in the late spring and summer and that these pathways vary significantly on intraseasonal to interannual timescales.

\subsection{Changes associated with the spring breakup of the polar stratospheric vortex}

The warming of the stratosphere between October and December is important for changes in the large-scale circulation as well as to boundary layer behavior at the SP (Neff, 1999). It has been noted by others that the final warming of the southern stratosphere has a significant influence on the tropospheric circumpolar circulation (Black and McDaniel, 2007). Furthermore, with the final warming, downward coupling (at wave-one scales) from the stratosphere to the troposphere ceases (Harnik et al., 2011), although the subsequent impact on the circumpolar storm track has not been explored. The timing of this final warming varies from year to year and is marked initially as the time the zonal wind in the polar vortex between $30-10 \mathrm{hPa}$ and $54-75^{\circ} \mathrm{S}$ first goes to zero. Harnik et al. (2011) found that this occurred very late in 1998 and very early in 2000; 2003 and 2006 followed the long-term trend toward a later warming. Of primary importance in the delay of the vortex breakup is the persistent low total column ozone and resulting increase in actinic flux later into spring (as in 1998) responsible for increased photolysis of snow nitrate.

In Fig. 2 we looked at the period 1990-2010, the two decades following the onset of rapid stratospheric ozone depletion that began in the 1980s. This depletion resulted in a 30 day delay in the formation of the thermal tropopause over the SP as documented in Fig. S5. Prior to 1980, the tropopause formed, on the average, around Julian Day 306 (2 November). After 1990, the average time is Julian Day 336 (2 December), a delay of 30 days. Past analyses calculated the covariance of fluctuations in the easterly component of the surface wind and temperature (essentially the easterly flux of cold air: $v^{\prime} T^{\prime}$ ) from 1961 to 1997 (Neff, 1999) finding a persistence of about 20 days later into the spring between 1961-1970 and 1988-1997 commensurate with the delay in the breakup of the polar vortex. This suggests that a delay in the breakup of the vortex leads to an increase in surface winds from the east to southeast quadrant associated with higher NO later in the spring which is not inconsistent with the results in Fig. S3a.

Figure S6 compares the seasonal change in total column ozone between 1964-1980 (these data are only available starting in 1964) and 1990-2010 (measured with a Dobson Ozone spectrophotometer - available from www.esrl.noaa. gov/gmd/ozwv/dobson/) showing reductions of about $30 \%$ in early December. The reduction in ozone now coincides with the period most favorable to southeast winds shown in Fig. 2 (with clear skies and shallow boundary layers important to high NO concentrations). In addition, changes shown in Fig. S6 suggest long-term increases in actinic flux with a $30 \%$ reduction in total column ozone by the average time of vortex breakup in recent decades. In addition, the largest changes occur between JD 320 and JD 330 corresponding to the periods of highest NO in 2003 and 2006 as shown in Fig. 1. A question that remains, however, is whether the distribution of winds aloft in Fig. 2 is an artifact of coincidental changes in the timing of the vortex breakup and the normal seasonal cycle in the circumpolar circulation or has, perhaps, been influenced by the effect of ozone depletion on the tropospheric circulation. Figure S7 explores this question in more detail with winds examined at both 200 and $300 \mathrm{hPa}$. In Fig. S7a and b for Days 270-305 ( October), the wind distributions are very similar to those of Fig. 2 for both 1960-1980 and 1990-2010. In Fig. S7c and d for Days 305-340 ( November) the bimodal distribution seen in Fig. 2 appear at both 200 and $300 \mathrm{hPa}$ as well as in both time periods although the trend is toward a more bimodal distribution at $200 \mathrm{hPa}$. This suggests that the wind aloft becoming bimodal in November is an artifact of the seasonal cycle rather than resulting from the breakup of the polar vortex. In Fig. S7e and f for Days 341-365 ( December), winds at $300 \mathrm{hPa}$ from the northwest are favored as in Fig. 2 with the effect a bit more evident in 1990-2010 compared to 19601980. However, at $200 \mathrm{hPa}$ the wind direction distributions are significantly different with a reversal of the distributions between the two 20 year periods. At both 200 and $300 \mathrm{hPa}$, winds aloft favor the northwest to north directions which are associated with increased cloudiness: this implies even less favorable conditions for high NO during the summer period. This change in the circulation may be associated with the stronger tropopause strength in the 1960s and 1970s (average difference of $6.7^{\circ} \mathrm{C}$ between 300 and $200 \mathrm{hPa}$ ) vs. recent decades $\left(1.6^{\circ} \mathrm{C}\right)$.

\subsection{Seasonal variation in cloudiness}

Shallow boundary layers occur most often with clear skies. With cloudy conditions the boundary layer is usually deep and well mixed (Neff et al., 2008). It has been noted that cloudiness has generally increased over Antarctica in recent decades (Neff, 1999; Schnell et al., 1991). Figure S8 shows an updated version of Plate 5 in Neff (1999) from 1957 to 2013 of average cloud fraction at the SP from winter to sum- 
mer. The figure shows a continued increase in cloudiness in late winter and summer after 1980 and a late spring minimum generally during Julian Days 325-350 as well as a late winter increase in cloud fraction in the most recent decade. The minimum in cloudiness during Julian Days 325-350, when shallow boundary development is likely due to increased clear sky radiative cooling and also coincides with increased actinic flux due to the persistent ozone hole of recent decades. This is also the period in 2003 and 2006 when the highest and most persistent NO occurred (in 1998, the field program started late and in 2000, the ozone hole filled early). Conversely, the summer period has, on the average, become cloudier, albeit subject to interannual and decadal variability, and hence less conducive to higher NO.

However, the average cloud fraction can vary within a season and from year to year. For example, the average cloudiness for days 310-340 (late spring) was 6.5, 5.1, 3.9, and 5.1 for 1998, 2000, 2003, and 2006, respectively. In 1998, the late spring period was particularly cloudy compared to average conditions. However, after a late start to observations (see Fig. 1), higher NO occurred intermittently later in December during days with clear skies, light winds, and higher actinic flux (due to the delay in the breakup of the ozone hole that year). The intermittency in 1998 is also reflected in the very limited values of NO in excess of 500 pptv (only $4 \%$ compared to $25 \%$ in 2003, Table 1) Fig. 5 shows an example of the importance of short-term variability in creating high NO episodes using an example from 2006 when a minimum in cloudiness occurred around JD 337 (3 December 2006) just before the photolysis rate for nitrate, $j\left(\mathrm{NO}_{3}^{-}\right)$started decreasing by $40 \%$. This decrease was associated with the breakdown of the winter stratospheric vortex and the attendant increase in ozone which results in decreased UV flux due to absorption in the stratosphere. Figure 5a summarizes the consistent timing of this cloud minimum showing the 2000-2010 average observer-based cloud fraction compared to that in 2006 (using 14 day running averages). Figure 5b, using three-day running averages, shows the timing of the cloud-fraction minimum in 2006 relative to the start of rapid warming and ozone increases in the lowermost stratosphere: the maximum in nitrate photolysis rate occurs just prior to the stratospheric warming as shown in the figure as well as in Fig. 5c. Figure 5c shows the direct solar irradiance for JD 335-340 (1-5 December) where decreases indicate the presence of clouds which affect the surface energy balance. The daily average cloud fraction (green bars - from the SP climatological record) shows close inverse agreement with the average direct solar irradiance. Starting on JD 337, skies clear, leading to the rapid formation of a surface temperature inversion below $10 \mathrm{~m}$ as seen on the $22 \mathrm{~m}$ tower. Several hours after the cooling starts, the winds shift from $\mathrm{N}$ to southeast (winds not shown), the inversion strengthens and hourly NO increases to nearly 800 pptv (1200 pptv in 10 min averages) despite a modest decrease in actinic flux. What is interesting in this case is the fact that even though the photolysis rate is decreasing, NO is increasing locally. What is unknown is whether high NO was generated earlier away from the SP and then transported into the site. This will be discussed more fully in Sect. 3.2. These results in this case still suggest the dominant role of a strong surface inversion, shallow boundary layer and potential for non-linear $\mathrm{NO}_{x}$ chemistry as suggested by Davis et al. (2004b).

\subsection{The role of local topography}

Figure 6 shows the local terrain within several hundred kilometers of the SP as well as the location of the clean air sector (340 to $110^{\circ}$ - where no potential contamination sources are allowed) and other areas of potential anthropogenic $\mathrm{NO}_{\mathrm{X}}$ sources $\left(210\right.$ to $340^{\circ}$ ) that depend on wind direction. As noted in the figure, the station power plant lies almost due west of the Atmospheric Research Observatory (ARO), whereas runways and aircraft taxiways and parking areas encompass much of the 210 to $340^{\circ}$ sector. To avoid potential contamination, data from this sector were removed from the analysis. Except for the power plant, other anthropogenic $\mathrm{NO}_{x}$ sources are likely to be intermittent and show up as large outliers and were also removed.

Although discussions of the slope flows at the SP generally assume an idealized sloped plane of great fetch, the local topography is much more complex as seen in Fig. 6. In fact, the terrain rises $250 \mathrm{~m}$ in the first $150 \mathrm{~km}$ to the east of the SP (slope $\sim 0.002$ ) just adjacent to an extensive plateau (slope $\sim 0.0003$ ) that begins $150 \mathrm{~km}$ east of the SP and extends $200 \mathrm{~km}$ to the foot of the relative steep central Antarctic dome that rises to $4 \mathrm{~km}$ a.s.l. to the northeast. In addition, a small "air drainage" basin about $100 \mathrm{~km}$ in extent lies to the southeast. The average surface wind direction from the northeast follows terrain isopleths for several hundred kilometers rather than flowing down a slope as is normally envisioned. However, while the average surface wind direction at SP is from the northeast along the terrain, the wind direction actually fluctuates between north (with warmer temperatures) and east (with colder temperatures). In the winter, the difference in the centers of the wind direction distributions for warming and cooling events is $90^{\circ}$ (Neff, 1999). The distribution for our summer experimental periods is narrower with maxima at 20 and $70^{\circ}$ and a relative minimum at $40^{\circ}$. Figure S9 shows an example of the distribution of $10 \mathrm{~min}$ NO concentrations as a function of wind speed and azimuth for 16-30 November 2006. In this case surface wind directions between 50 and $150^{\circ}$ and speeds less than $5 \mathrm{~m} \mathrm{~s}^{-1}$ account for most of the high NO concentrations, consistent with Fig. 4. These directions align closely with the shallow basin to the east-northeast and southeast of the SP (Fig. 6). 
(a)

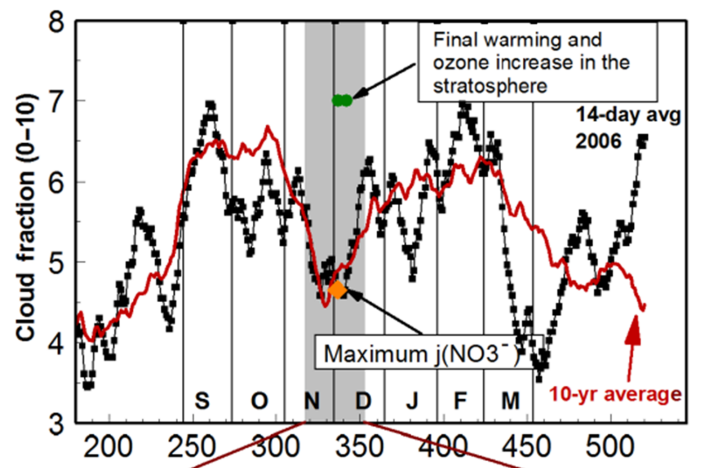

(b)

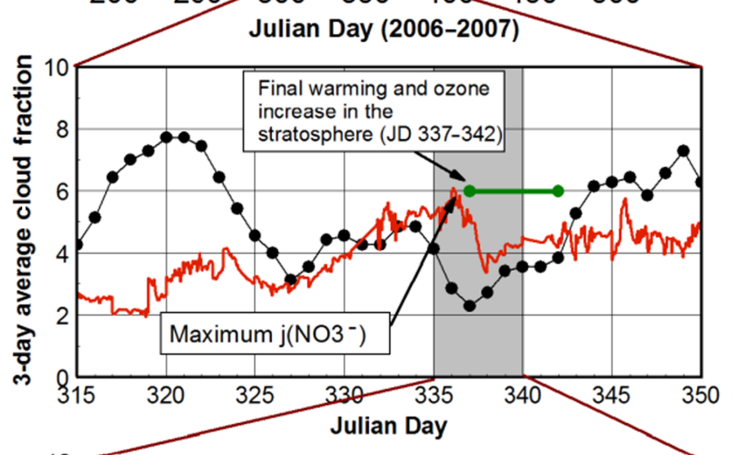

(c)

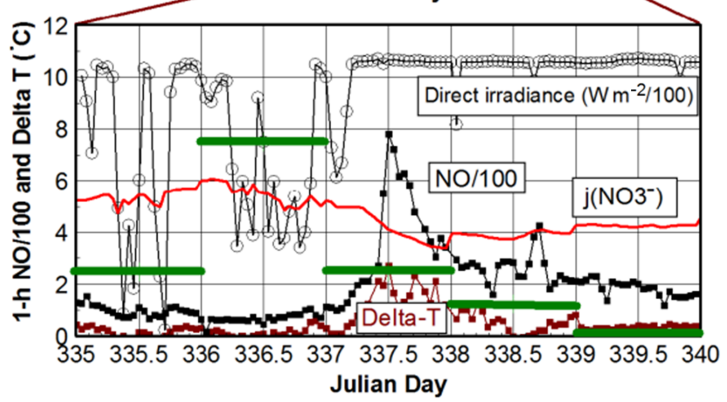

Figure 5. (a) Time series of observer-derived cloud fraction averaged for 2000-2010 (red line) at the SP and the field season of 2006-2007 (black line) showing the consistency of individual years with the long-term average. A 14 day running average (red line) was used. The period of final warming of the stratosphere in $2006\left(t_{200 \mathrm{hPa}}-t_{300 \mathrm{hPa}}>0\right)$ and the period of rapid increase in total column ozone are indicated symbolically for JD 337-342. The date of the maximum in $j\left(\mathrm{NO}_{3}^{-}\right)$is indicated by an orange diamond (Day 336) from Davis et al. (2010). (b)The expanded time series of cloud fraction for JD 316-350 showing relative minima on JD 327 and JD 337 as well as the timing for the breakdown of the ozone hole (as seen in $j\left(\mathrm{NO}_{3}^{-}\right)$nitrate photolysis rate coefficients scaled for plotting) and stratospheric warming. (c) Expanded view of NO, $\Delta T(2-10 \mathrm{~m}), j\left(\mathrm{NO}_{3}^{-}\right)$(scaled for plotting), and direct radiance time series for JD 335-340. Daily cloud fraction, derived from climatological observer records, is shown using green bars. Note the decrease in $j\left(\mathrm{NO}_{3}^{-}\right)$prior to the increase in NO.

\subsection{Possible meteorological precursors to high NO}

We have shown the dependence of $\mathrm{NO}$ on $10 \mathrm{~m}$ wind speed and direction (Figs. 4 and S9). However, in both 2003 and 2006, prolonged and high NO occurred in the last half of
November (Fig. 1). This raises the question of whether antecedent conditions set the stage for high NO. In particular, past studies such as Mahesh et al. (2003), have noted the systematic change in wind speed between November and December and also concluded that blowing snow was prevalent at the SP when the wind exceeded about $7.5 \mathrm{~m} \mathrm{~s}^{-1}$ which was more likely in November. Figure S10 shows the $1 \mathrm{~min}$ wind speed distributions between November and December for the four ANTCI seasons revealing the much higher prevalence of winds in excess of $7.5 \mathrm{~m} \mathrm{~s}^{-1}$ in November. Table $\mathrm{S} 1$ shows a more detailed breakdown of the number of hours of winds exceeding $7.5 \mathrm{~m} \mathrm{~s}^{-1}$ for October, November, and December for each of 1998, 2000, 2003, and 2006. Unlike the other field experiment years, 2003 saw the fewest high winds in November and the greatest number in December (although light winds only prevailed after 10 November). Snow stake-field depth data in 2003 showed an increase in snow depth of $6.1 \mathrm{~cm}$ in October, whereas November showed a decrease of $1 \mathrm{~cm}$ (from Local Climatological Data records - ftp: //amrc.ssec.wisc.edu/pub/southpole/climatology/). A coincidence between blowing snow and increased surface nitrate has been observed at Halley Station (Mulvaney et al., 1998) where high wind events in November coincided with increased accumulation followed by a lowering of the snow surface though processes including sublimation and metamorphosis such as also observed in 2003 at the SP. Following the high wind period at Halley Station, a factor of 4 increase in surface snow nitrate concentrations was seen (followed by significant losses over the subsequent 10 days). The results of Mulvaney et al. (1998) suggest that one possibility for this increase was scavenging by wind-blown snow crystals of air rich in nitric acid during the high wind period followed by the loss of water vapor via sublimation resulting in higher concentrations of nitrate on the surface. Recent research at Concordia Station on the high Antarctic Plateau reported a similar increase in surface nitrate in early December (Berhanu et al., 2015). Wind speed had been high in late November (Frey et al., 2015) followed a week later by high skin nitrate and high fluxes of $\mathrm{NO}_{x}$ from the surface consistent with the observations of Mulvaney et al. (1998) at Halley Station.

\section{Case studies and insights from new 2006 data in the context of past experiments}

Figure 1 provided a summary of all four field programs. Here we focus on events that reflect the coupling of boundary layer meteorology and chemistry using the unpublished data set obtained from 2006 to early 2007 and compare these findings with previous field studies. Of the four field periods, 2006-2007 was the only one to capture the early spring to summer transition in meteorology and chemistry. To provide an overview of the seasonal evolution and short-term weather events on near-surface NO concentrations in 2006, Fig. 7 shows the time series of NO, wind direction, wind speed, 


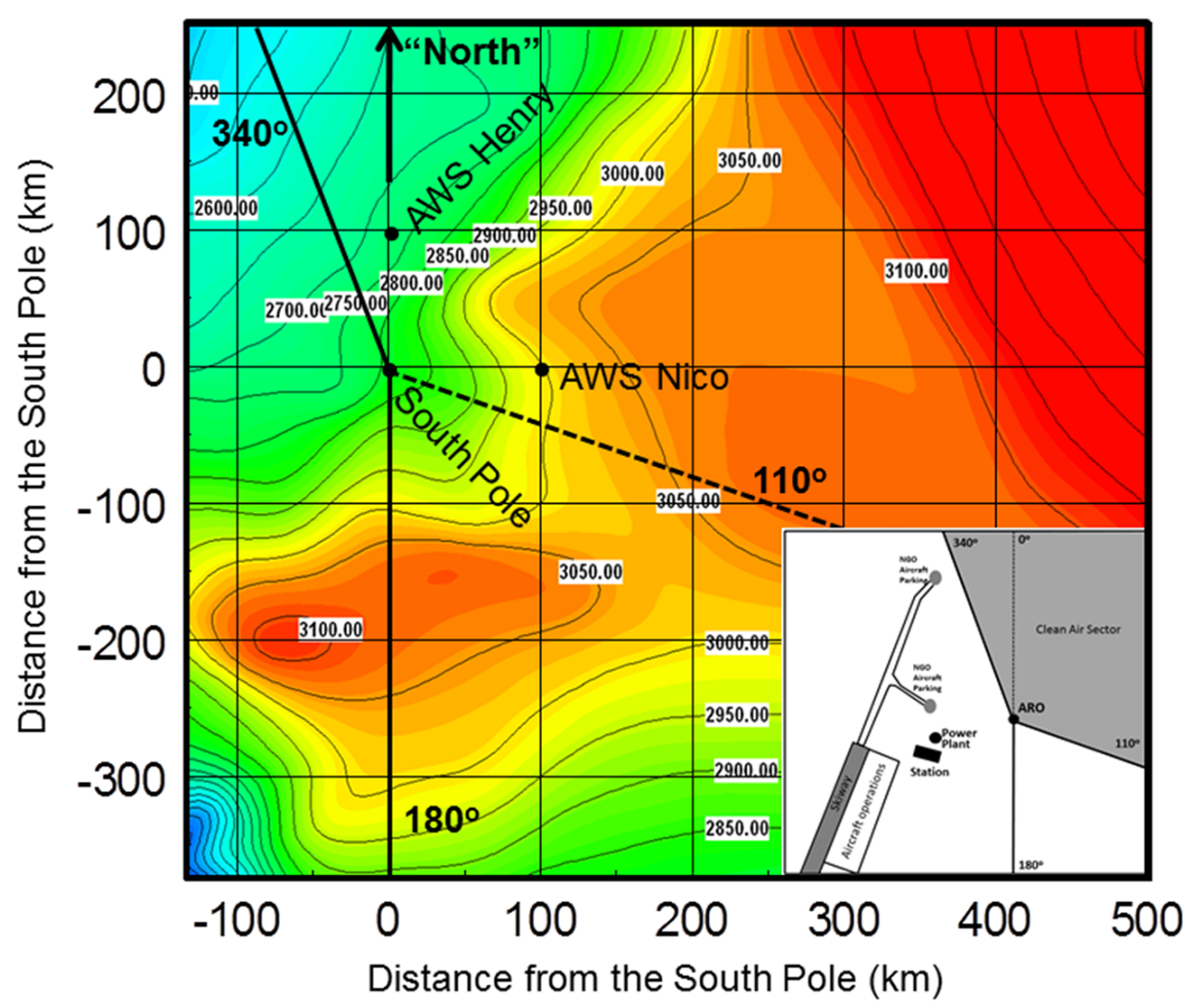

Figure 6. Local terrain around the SP and the location of station facilities and the clean air sector (map insert). Contour interval is $50 \mathrm{~m}$. The clean air sector extends from 340 to $110^{\circ}$, whereas the major station activity is located between 340 and $210^{\circ}$. Note that the prevailing surface wind (northeasterly) is actually along terrain isopleths upstream of the station except for the last $50 \mathrm{~km}$. Local "downslope winds" come from directions generally between east and south. Automatic Weather Stations (AWS) Nico and Henry, which have been operating since 1993 are also indicated lying about $100 \mathrm{~km}$ from the SP. Highest NO is observed when the wind directions are from the direction of the terrain "gap" to the southeast of the Station.

and temperature from 1 November 2006 (Day 305) through 13 January 2007 (Day 378) with eight events highlighted and labeled " $\mathrm{A}$ " through " $\mathrm{H}$ ". In addition, hours of relatively clear skies (high direct irradiance $>80 \%$ of maximum) are indicated on the temperature plot with hash marks plotted at $-20^{\circ} \mathrm{C}$ on the temperature time series panel. In general, high direct irradiance associated with a lack of clouds, implies a net loss of radiation from the surface because of the cold dry atmosphere that prevails over the SP, high albedo, and the lower sun angle compared to other polar sites.

In each of these cases in 2006, higher NO follows the clock-wise rotation of the wind past $60^{\circ}$ together with slight to moderate drops in temperature (see Fig. 4). The duration in each case ranges from less than a day to multiday periods. Episodes "A to C" follow high wind episodes by 2 to 3 days. Episode A in Fig. 7 reveals a rapid increase in $\mathrm{NO}$ as the wind shifts to the east and weakens, followed by a rapid decrease as the wind increases to $10 \mathrm{~m} \mathrm{~s}^{-1}$ and shifts to northerly. Episode "B" follows several periods of winds reaching $10 \mathrm{~m} \mathrm{~s}^{-1}$ until JD 320 (16 November) followed by lighter winds from easterly directions and persistently high NO for almost ten days. During the period of high NO in "B", winds at $300 \mathrm{hPa}$ were consistently from the southeast, an artifact of a persistent, elongated trough of low pressure over the higher terrain grid northeast of the SP (see also Fig. S2). Episode "C" was explored in the example shown in Fig. 5 and will be discussed more fully below. Episodes "D-G" represent short excursions of NO and all occur with lower wind speeds and occasional easterly directions. Episode " $\mathrm{H}$ " is included because of its contrast with early periods and its occurrence as one of the few "events" available during the summer period: " $\mathrm{H}$ " begins with the temperature exceeding $-20^{\circ} \mathrm{C}$ and then dropping to between -30 and $-25^{\circ} \mathrm{C}$ with the arrival of a cold front and clear skies. The highest temperatures, above $-20^{\circ} \mathrm{C}$, occurred during totally overcast skies, a weak inversion, and NO concentrations less than $100 \mathrm{pptv}$. Later, there were periodic wind shifts to the east, clear skies, light winds and colder temperatures, and higher but modest levels of NO (200-300 pptv). In this case, NO levels remained only moderate despite weak easterly winds, 


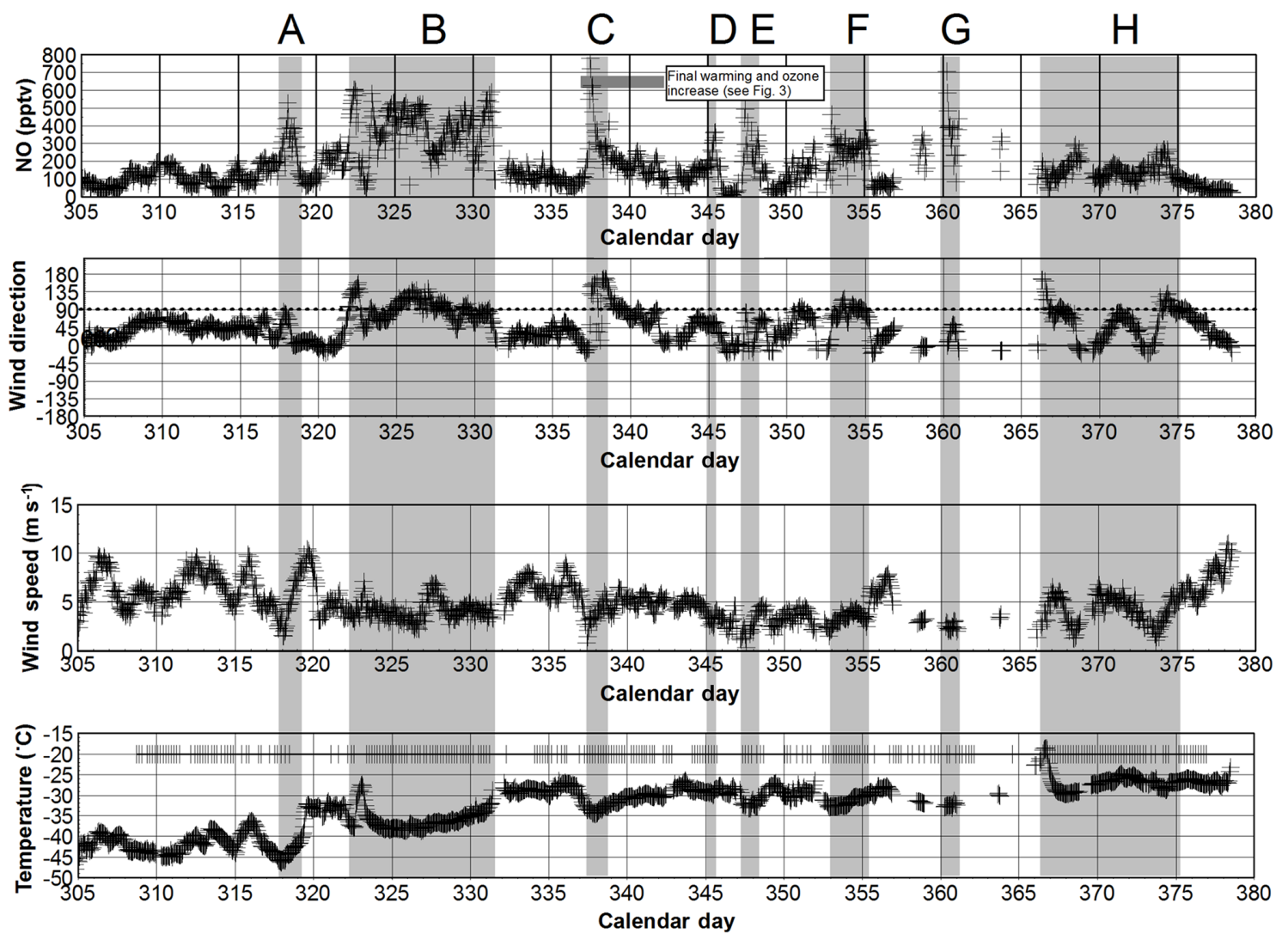

Figure 7. Time series of NO, wind direction, speed and $2 \mathrm{~m}$ temperature for November 2006 through mid-January 2007 (Days 305-380). Data gaps at the end of December are due to either missing NO and/or meteorological data. Shaded areas and labels A-H are cases where $\mathrm{NO}>300$ pptv. Case "C" is that highlighted in Fig. 5 which occurs at the time of stratospheric warming and total column ozone increase. The wind azimuth of $60^{\circ}$ is also noted (corresponding to Fig. 4 for directions associated with higher NO). Periods of clear skies are indicated on a four-hourly basis by hash marks at $-20^{\circ} \mathrm{C}$ on the temperature plot: note the increase in temperature around JD 320 associated with cloudy skies, increase in wind speed, and shift in wind direction from east to north.

increased inversion strength, a shallow boundary layer, and a longer potential fetch.

\subsection{NO levels before and after the final warming of the stratosphere}

Of particular interest in 2006 is the fact that Episode "C" occurred just prior to the final warming of stratosphere (Fig. 5). As noted earlier, from 1990 to 2010, this warming occurs on the average on Day 336 and coincides with the transition in the seasonal cycle as summarized in Fig. 2. Comparing NO levels for 20 days before and after Episode "C", $20 \%$ of hourly NO levels $>400$ pptv occur before (JD 305-340) and only $6 \%$ occur after (JD 340-360). Similarly, in 2003, $43 \%$ of hourly NO levels $>400$ pptv occur before (JD 326335 ) and only $10 \%$ occur after (JD 340-360). In both 2003 and 2006 high NO events were typically associated with periods of southeast winds aloft. Table S2 shows the breakdown of southeast $\left(45-225^{\circ}\right)$ and northwest $\left(225-360^{\circ}\right)$ winds at $300 \mathrm{hPa}$. For both 2003 and 2006 the distributions of wind directions for JD $<340$ are very similar but the average NO differs by a factor of 2 (2003: 445 pptv; 2006: 247 pptv). For JD > 340, 2003 has many more northwest winds than 2006 but similar average NO (200 pptv in 2003 and 175 pptv in 2006). In 2003, $300 \mathrm{hPa}$ wind distributions were consistent with long-term averages (1990-2014), whereas 2006 was an anomaly in early summer with far fewer northwest winds aloft and many more from the southeast (see Fig. 3). Comparing these two years reveals the complexity introduced by meteorology: in $2003 \mathrm{NO}$ was fairly low after JD 340 during a period of higher winds and cloudy conditions but then followed by a single high NO episode near the end of the month, whereas 2006 saw sustained moderate NO concentrations throughout the period (see Fig. 1). Thus the much lower average NO after JD 340 in both years appear consistent with the conclusion from Frey et al. (2015) for the last half of December and early January at Concordia Station. Frey et al. (2015) argues, based on the laboratory results of Meusinger et al. (2014) that the snow nitrate is composed of both a photo-stable and photo-labile fraction and that the photo-labile fraction decreased later in December at Concor- 
dia Station. Our results would be consistent with that interpretation and show the value of multi-year and intraseasonal comparisons of NO. In addition, as noted in Sect. 2.2, 2003 was unusual with a reduction in snow heights in November, whereas 2006 saw continuous increases in snow depth through November which may have reduced the exposure of surface nitrate to photolysis and recycling.

It should be noted that we did not consider 1998 or 2000: in 1998, the breakup of the vortex was much delayed, whereas in 2000 it was very early (Harnik et al., 2011; Neff, 1999). Figure 1 summarized the spring cycle in NO levels and extremes showing hourly NO concentrations for all four years as well as the day on which total column ozone at the SP first exceeds 300 DU. The figure showed that 2003 and 2006 are similar in sustained high NO in late November with a few isolated peaks in late December (typically with light winds, strong surface inversions, and clear skies). It should be noted that the 2003 peaks in NO in late November stand out as the highest in all four years. As noted earlier, this was also a period of lowest cloud fraction and light winds. In 2000, the ozone hole filled in early November coincident with the breakup of the polar stratospheric vortex: NO concentrations stayed very low through the entire observation period. In 1998, the ozone hole filled briefly near the end of December followed by a very delayed (until the end of January 1999) formation of the thermal tropopause due to a cooler than normal lowermost stratosphere.

\subsection{Meteorological and other potential local and external influences on NO concentrations}

Figures 2-5 revealed that there were well defined meteorological regimes that favored high NO concentrations that involved wind directions aloft from the southeast, surface winds from the east, and a surface energy balance that was strongly influenced by clear sky conditions. Past work has indicated that the SP is not isolated from the influence from more northerly latitudes. For example, high methanesulfonate was observed from 28 November to 2 December 2003 - an indication of marine sources (Arimoto et al., 2008). This period had the highest NO values recorded in the entire series of field programs (Davis et al., 2008) similar to those found at Concordia in a similar time frame in 2011 (Frey et al., 2015). Furthermore, as suggested in Arimoto et al. (2008) air arriving at the SP may have had its origins in continental regions (due to much higher concentrations of the elements $\mathrm{Pb}$, $\mathrm{Sb}$, and $\mathrm{Zn}$ than in previous field programs) as well as in the ocean off Wilkes Land on the far side of the continent.

The conceptual description of Arimoto et al. depended on the December 2003 mean geopotential pattern which reflected a large high pressure region over East Antarctica and its large-scale counter clockwise circulation. However, the pattern for the ten days prior to 4 December 2003, when NO was the highest, was much more complex as shown in Fig. S11, with lower GPH over most of the continent and deep lows over the southern Weddell Sea, Enderby Land and Victoria Land all in position to provide transport of air from more northerly latitudes. Figure S12 shows the ERAI trajectory for air at $700 \mathrm{hPa}$ arriving near the SP at $12 \mathrm{Z}$ on 30 November 2003 from the vicinity of Wilkes Lake which extends between about 100 and $140^{\circ} \mathrm{E}$. The period after 4 December was consistent with the pattern described by Arimoto et al. (2008) with much higher GPH over East Antarctica. This leaves the question of the origins of high snow nitrate in late winter/early spring open, insofar as October to early November is a period of vigorous transport from latitudes north of Antarctica following the maximum in the semi-annual oscillation and as evidenced by high cloud fraction (Neff, 1999).

Episode " $\mathrm{C}$ " is quite interesting seeing that it is preceded by a period of high winds and a rapid surface wind shift from north to southeast following the winds at $300 \mathrm{hPa}$. Figure 8 shows this case in more detail using wind data from the SP and AWS stations Henry ( $100 \mathrm{~km}$ along $\left.0^{\circ} \mathrm{E}\right)$ and Nico $\left(100 \mathrm{~km}\right.$ along $\left.90^{\circ} \mathrm{E}\right)$ as seen in Fig. 6 . These data show that as the wind speed aloft drops, the surface wind speed also drops to less than $0.5 \mathrm{~m} \mathrm{~s}^{-1}$ albeit sequentially first at Henry, then Nico, and finally at the SP. The increase in NO follows a surface wind direction shift and increase in speed from the southeast that appears first at Henry and then four hours later at the SP. These shifts are quite abrupt, whereas that at Nico is more gradual. The increase in NO at the SP does not coincide with the drop in wind speed to $0.5 \mathrm{~m} \mathrm{~s}^{-1}$ (which would have implied local accumulation or local sources) but rather follows during an increase in wind speed with the wind direction shift to the southeast (from the basin shown in Fig. 6.) This suggests a hypothesis that this basin to the southeast is an accumulation area for high NO that is exhausted after an hour or two (see Fig. 8: with wind speeds of $2-4 \mathrm{~m} \mathrm{~s}^{-1}$, transport distances of 7 to $14 \mathrm{~km} \mathrm{hour}^{-1}$ might be inferred).

Tracing the progression of the event through the AWS and the SP, suggests that the event is triggered by a mesoscale disturbance propagating from the northeast that leads to boundary layer changes. However, referring to Fig. 8d, it appears that clearing skies quickly result in a low-level radiation inversion and associated shallow BL in which NO can accumulate. The $22 \mathrm{~m}$ tower data show that most of the radiative cooling is felt below $10 \mathrm{~m}$. Of interest in this case is the greater contribution of mesoscale processes relative to the potential influence of katabatic forcing. Figure 9 shows geopotential and wind field at $650 \mathrm{hPa}$ from ERA-I $(\sim 300-$ $400 \mathrm{~m}$ above the surface at the SP) during this event at $12 \mathrm{Z}$, JD 337 (3 December) between 90 and $75^{\circ}$ south. In this case a small mesolow formed to the west of the SP and rotated cyclonically to just north of the SP over $24 \mathrm{~h}$. It then intensified further north bringing air over longer distances from the east to northeast back to the station but with a reduction of NO to about 200 pptv over the following day. The rawinsonde at $1048 \mathrm{Z}$ on Day 337 recorded winds from the northeast at $8 \mathrm{~m} \mathrm{~s}^{-1}$ below $100 \mathrm{~m}$. By $2120 \mathrm{Z}$ the rawinsonde 

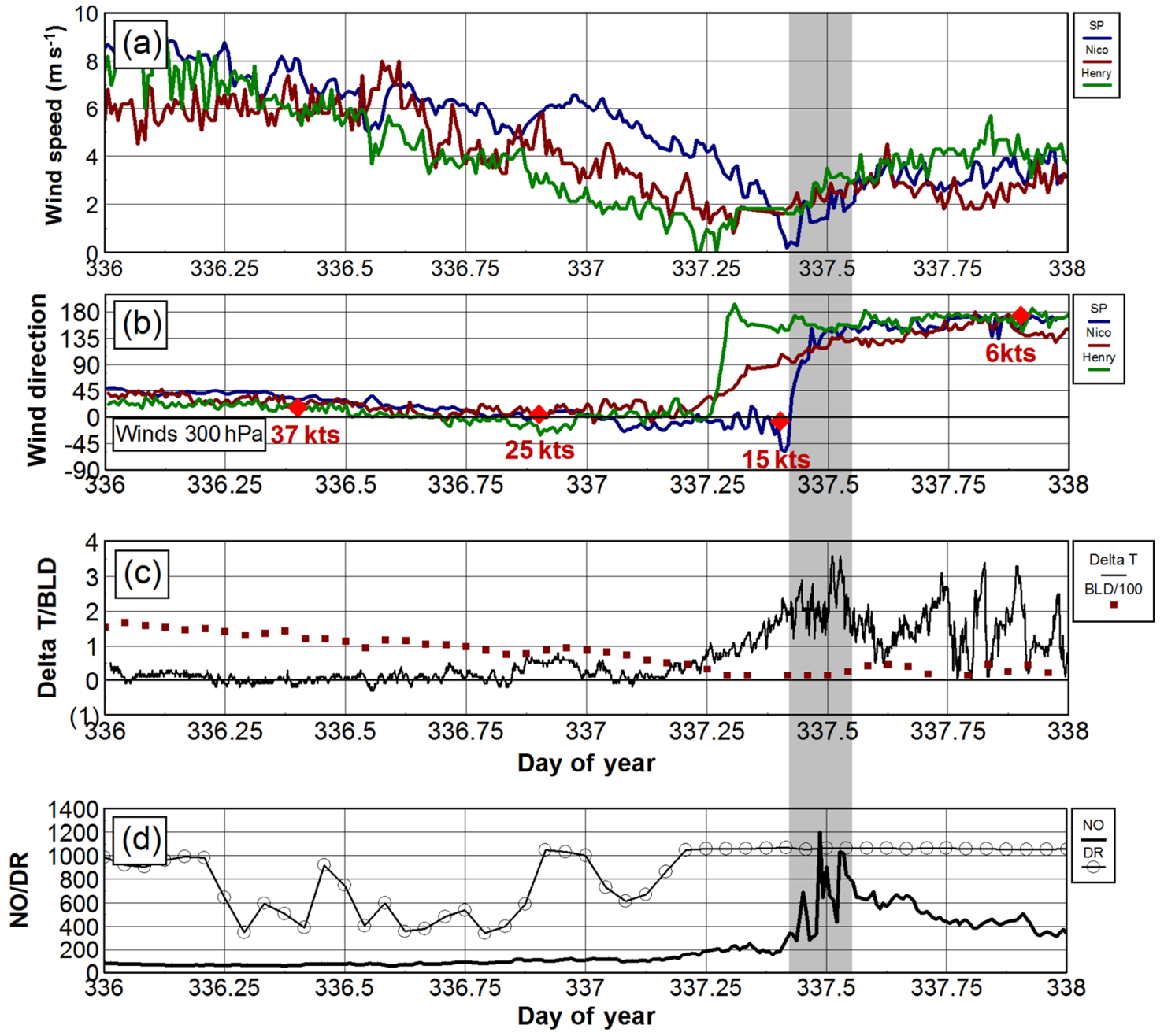

Figure 8. Time series of (a) wind speed, (b) direction (c) $\Delta T$ and BLD and (d) NO and direct radiance (DR) for Days 336-338, 2006 (Case C in Fig. 7). In (b) we indicate wind speed and direction at $300 \mathrm{hPa}$ (red diamonds) at the actual launch times of the rawinsondes (generally $2-3 \mathrm{~h}$ prior to reporting times of $00 \mathrm{Z}$ and $12 \mathrm{Z}$ ). Of note is the decrease in surface wind speeds from over $8 \mathrm{~ms}^{-1}$ (sufficient for blowing snow) that follow the same trend as at $300 \mathrm{hPa}$. We have also indicated the BLD calculated later in Appendix A that shows the rapid decrease in BLD.

showed winds increasing in the lowest $100 \mathrm{~m}$ approaching $10 \mathrm{~m} \mathrm{~s}^{-1}$. It is instructive to compare these winds to those estimated from katabatic arguments. An estimate of the katabatic acceleration can be obtained from the following: acceleration $=9.8 \mathrm{~ms}^{-2} \times \Delta T / T \times \sin (\alpha)$. With $\Delta T=2{ }^{\circ} \mathrm{C}$, $T=250 \mathrm{~K}$, and terrain slope, $\sin (\alpha)=0.002$ (from Fig. 6), the acceleration is $\sim 0.5 \mathrm{~m} \mathrm{~s}^{-1}$ per hour. Four hours at this acceleration rate would lead to a wind speed of $2 \mathrm{~m} \mathrm{~s}^{-1}$ and a transport distance of several tens of $\mathrm{km}$. In this case katabatic effects can only account for a small portion of the local circulation and Fig. 9 shows the dominance of meso-tosynoptic-scale eddies in producing transport across the ice sheet. In particular, the small meso-low moved clockwise around the SP until at $18 \mathrm{Z}$ it was in position to accelerate easterly flow at the surface. With NO decreasing to $200 \mathrm{pptv}$ following the initial peak of $800 \mathrm{pptv}$ in the prolonged northeasterly flow, one might reasonably assume that the initial extreme in this case resulted from short-term boundary layer effects but that prolonged levels of 200 pptv are fetch related and reflect accumulation and/or dilution upwind or transport from longer distances.

The above example of the role of the rapid onset of surface radiative cooling as clouds clear is analogous to observations from Concordia Station (Frey et al., 2015), which is subject to a strong diurnal cycle and show a similar rapid collapse in BLD in the late afternoon as the surface cools through long-wave radiation. Even though the actinic flux decreases dramatically relative to its value at local noon at Concordia, the BLD collapses even more rapidly as the production of $\mathrm{NO}$ into the BL continues, leading to increases in NO to 0.3 

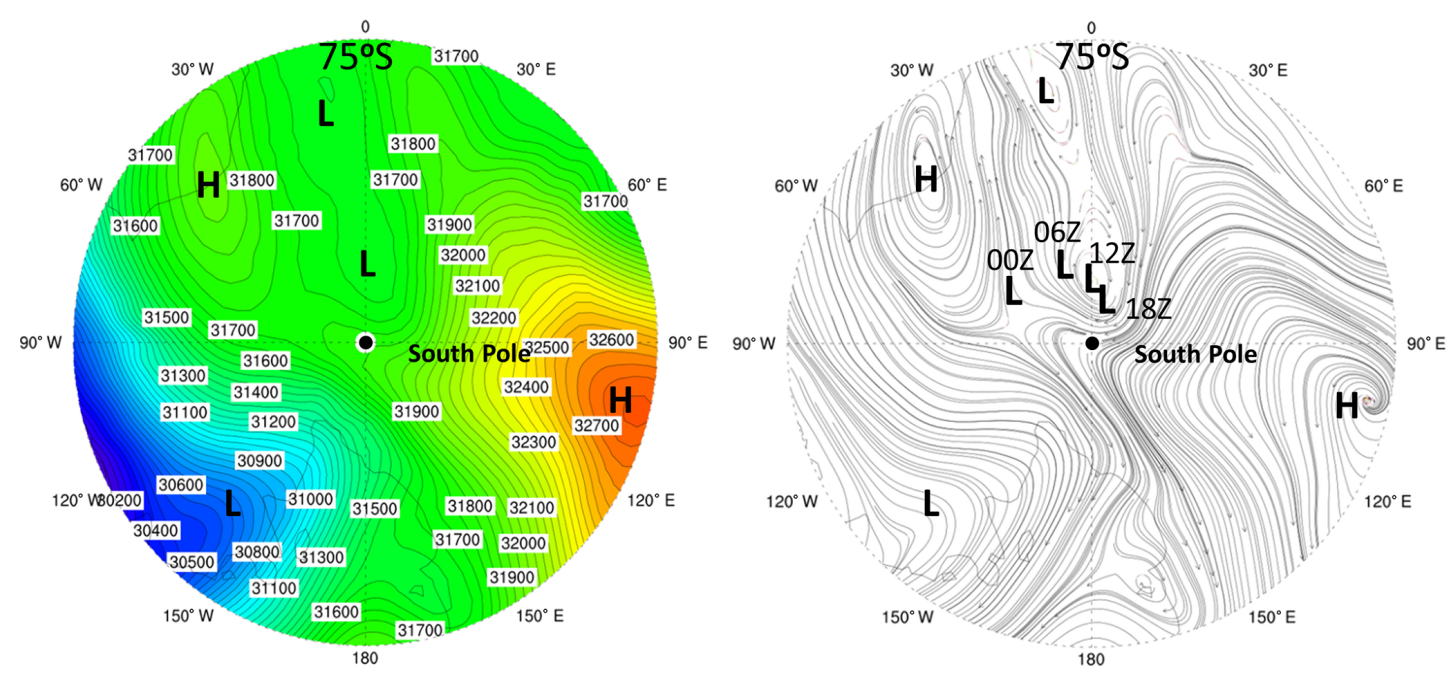

Figure 9. Geopotential at $650 \mathrm{hPa}$ at $12 \mathrm{Z}$ on JD 337 (3 December 2006) and wind field (using curly vector representation) from ERA-I (Dee et al., 2011). A trough of low geopotential lies along $0^{\circ}$ with higher geopotential and anticyclonic winds over the high plateau. Lows and highs are indicated, in addition to the location of a small cyclonic circulation, at $6 \mathrm{~h}$ intervals on JD 337 that brought easterly winds to the SP. By $12 Z$ on JD 338, the low to the north-northeast had intensified and produced consistent northeasterly winds at SP.

to $1.0 \mathrm{ppbv}$ (Frey et al., 2015). It was also concluded by Frey et al. (2015) that the rapid increase in NO with the collapse of the boundary layer in the early evening suggests that nonlinear $\mathrm{HO}_{X}-\mathrm{NO}_{x}$ chemistry need not be invoked in these cases. The case in Fig. 9 suggests that smaller enhancements of NO (e.g., less than $200 \mathrm{pptv}$ ) occur with longer fetches when NO can accumulate but large excursions, such as those in Fig. 8, respond to rapid changes in the surface energy budget that lead to very shallow inversion layers. The subsequent evolution of $\mathrm{NO}$ would then depend on chemical processes as well as changes in boundary layer mixing, such as those due to increased wind speeds. Figure 8 also suggests limitations in correlating surface NO with wind shifts at $300 \mathrm{hPa}$ : in this case the peak in NO occurs before the shift in winds aloft; by the next rawinsonde $12 \mathrm{~h}$ later NO has dropped substantially. Given the apparent sensitivity to surface cooling under clear sky conditions, Fig. 10 shows the relationship between the magnitude of direct solar irradiance, $\mathrm{NO}$, and surface wind direction. In Fig. 10a, NO $>400$ pptv only occurs when skies are essentially cloud-free, whereas in Fig. 10b, wind directions $>45^{\circ}$ are associated with clear skies. Conversely, more persistent cloudy conditions and surface winds from the west to north-northwest are associated with lower NO. The few outliers for wind azimuths $>45^{\circ}$ indicate the presence of occasional scattered clouds (in hourly data).

\subsection{BLD calculated for $1998,2000,2003$, and 2006 data}

Given the success of the multiple linear regression technique described in Appendix A which used $22 \mathrm{~m}$ meteorological tower data with 2003 sodar data to develop regression equations which were then tested against independent data from 1993, we computed hourly BLD for each of the four years during which NO measurements were recorded. The main time period addressed by these estimates was from midNovember (or somewhat later if data collection started later) to the end of December (for consistency). The next step was to test these data for the inverse relationship between NO and BLD as was found for 2003 (Davis et al., 2004b; Neff et al., 2008). If one bins the data to average out short-term fluctuations (Davis et al., 2004b; Neff et al., 2008), one finds a close inverse relation as shown in Fig. 11. Here we averaged BLD for 100 pptv bins of NO. Earlier results (Davis et al., 2004b; Oncley et al., 2004) applied empirical surfacelayer similarity relations to observations of turbulence scales in the surface-flux layer to determine BLDs in the 2000 data set. In their results they found BLD between $\sim 80 \mathrm{~m}$ and $\sim 500 \mathrm{~m}$ (Davis et al., 2004b) when they binned NO and BLD in sequential 30-point averages. In Fig. 11, for 2000, our binned BLD data fell between 28 and $100 \mathrm{~m}$, a factor of $\sim 3$ less in total range. A key argument for high NO at the SP has been the presence of shallow boundary layers which Fig. 11 confirms. However, in contrast, direct measurements of BLD at Summit Station Greenland (3216 m a.s.1., 72.6 $6^{\circ}$, $38.5^{\circ} \mathrm{W}$ ) show values of $\mathrm{NO}$ in the range of only $10-30 \mathrm{pptv}$ with BLD on the order of $5 \mathrm{~m}$ (Van Dam et al., 2013). One potential explanation for this difference is the high snow accumulation rate in the summer at Summit Station of 5.0 to $7.5 \mathrm{~cm}$ month $^{-1}$ in the summer, maximizing in July (Castellani et al., 2015). 

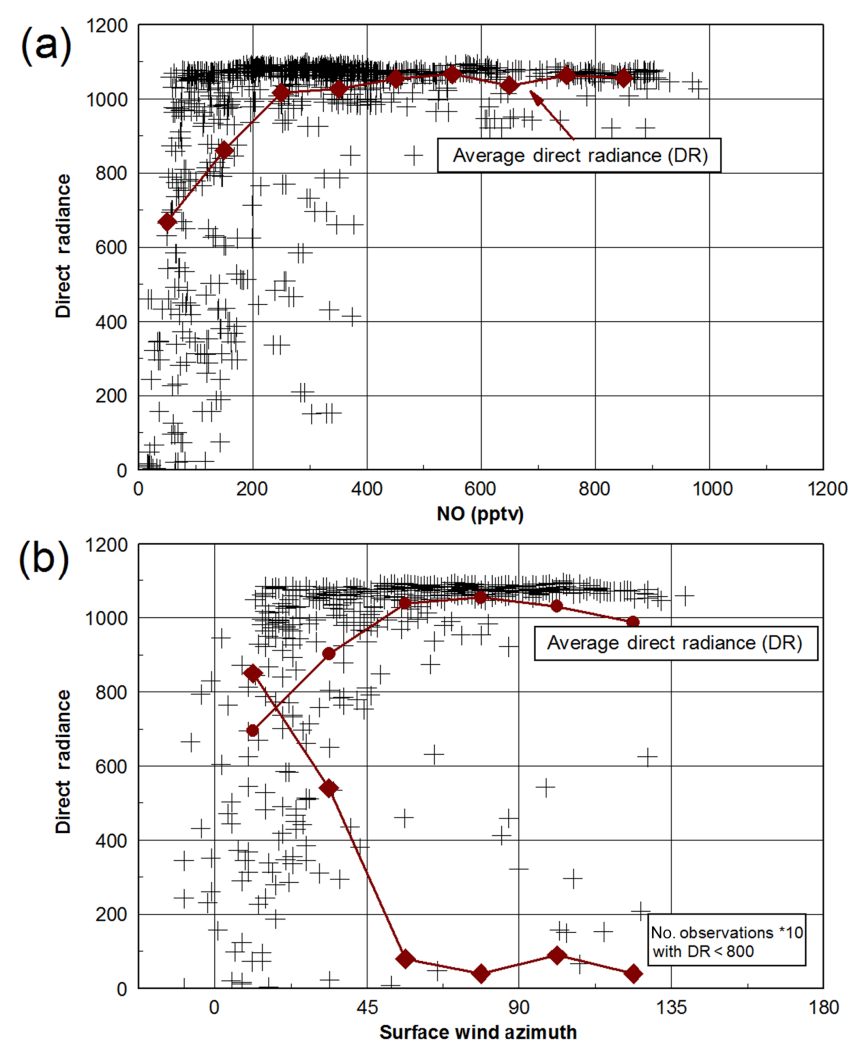

Figure 10. (a) Direct radiance (DR) vs. NO (hourly) for 2003 showing that values of $\mathrm{NO}>400 \mathrm{pptv}$ occur with virtually clear skies (DR $>80 \%$ of the maximum). (b) Direct radiance vs. surface wind direction (hourly) for 2003 with average DR and number of observations in 45 degree bins, showing cloudy to partly cloudy conditions prevail with surface wind directions less than $45^{\circ}$.

\section{Estimating seasonal $\mathrm{NO}_{x}$ emission fluxes for the SP region}

The development of a robust method for estimating BLD opens the door to estimating seasonal $\mathrm{NO}_{x}$ emission fluxes. This is based on the assumption that the surface flux is in balance with the photochemical loss of $\mathrm{NO}_{x}$ in the overlying BL column. These flux estimates require several factors to be considered. First, the total $\mathrm{BL} \mathrm{NO}_{x}$ must be extrapolated from the near-surface measurement of NO. While only NO was measured in previous years, the 2006 measurements included both $\mathrm{NO}$ and $\mathrm{NO}_{2}$. Based on those measurements, $\mathrm{NO} / \mathrm{NO}_{x}$ was found to be $0.65 \pm 0.08$. This is consistent with $\mathrm{NO}_{x}$ estimates derived from model calculations in previous years (Chen et al., 2001, 2004). Those calculations also indicate that the $\mathrm{NO}_{x}$ lifetime exhibits nonlinear behavior increasing from $\sim 7.5 \mathrm{~h}$ when $\mathrm{NO}_{x}$ is less than 200 pptv to more than $20 \mathrm{~h}$ when $\mathrm{NO}_{x}$ exceeds $600 \mathrm{pptv}$ (Davis et al., 2004b). Along with these effects, tethered balloon measurements at SP during ANTCI 2003 show that the exponential roll off in $\mathrm{NO}$ concentrations from the surface to

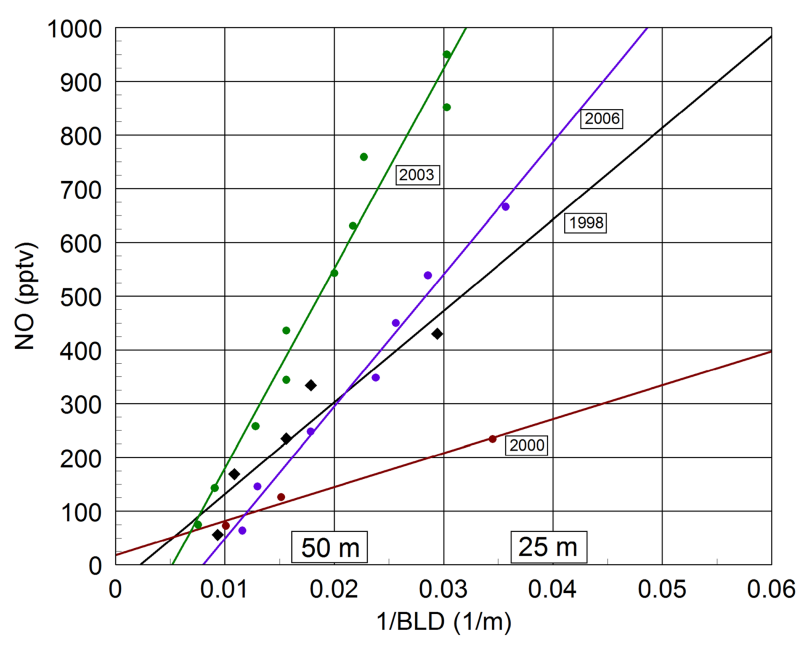

Figure 11. NO vs. 1/BLD for BLD averaged for each 100 pptv bin of NO. $r^{2}$ is as follows: 1998: 0.88; 2000: 0.98; 2003:0.97; and 2006: 0.98 .

the top of the boundary layer can often be as much as a factor of 5 for very shallow boundary layers (Helmig et al., 2008; Neff et al., 2008). Using these vertical profiles, the BL column $\mathrm{NO}_{x}$ abundance can be derived from surface $\mathrm{NO}$ observations. Given that the roll off in NO may not always be as severe as a factor of 5, these are considered to be conservative estimates of the total $\mathrm{BL} \mathrm{NO}_{x}$.

Seasonal $\mathrm{NO}_{x}$ emission fluxes are generated by taking daily average values of NO measurements and BLD estimates (appertaining to Appendix A). Based on the assumptions listed above, a total $\mathrm{BL} \mathrm{NO}_{x}$ and associated lifetime are estimated. The flux is then equivalent to the total $\mathrm{BL}$ $\mathrm{NO}_{x}$ divided by the lifetime. It is important to do this calculation daily since changes in BLD can cause total $\mathrm{BL} \mathrm{NO}_{x}$ and lifetime to vary in different ways. Results for the four seasons as summarized in Table 2 are 12.5, 6.3, 13.7, and $9.1 \times 10^{8}$ molec cm $^{-2} \mathrm{~s}^{-1}$ for $1998,2000,2003$, and 2006, respectively, assuming a fall-off factor of 5 . These values are commensurate with expectations from Fig. 11, with the highest seasonal flux in 2003 and the lowest in 2000. As can be seen in Fig. 12, NO concentrations at $\mathrm{BLD}^{-1}=0.03 \mathrm{~m}^{-1}$ (from Fig. 12) scale almost linearly with the seasonal average flux $\left(r^{2}=0.7\right)$.

Each year shows similar variability in daily flux estimates with SDs of 0.4-0.5 $\left(10^{8}\right.$ molec $\left.\mathrm{cm}^{-2} \mathrm{~s}^{-1}\right)$. These estimates are generally consistent with other published flux estimates for the Antarctic plateau. Oncley et al. (2004) estimated a flux of $3.9 \times 10^{8}$ molec $\mathrm{cm}^{-2} \mathrm{~s}^{-1}$ at SP in 2000 over several days at the end of November 1998, which is essentially in agreement with the seasonal estimate for this work. Likewise, flux observations at Dome $\mathrm{C}$ have been found to range from $8.2 \times 10^{8}$ to molec $\mathrm{cm}^{-2} \mathrm{~s}^{-1}$ in 2009-2010 to $1.6 \times 10^{9}$ molec cm $\mathrm{cm}^{-2} \mathrm{~s}^{-1}$ in 2011-2012 (Frey et al., 2015, 
Table 2. Assessment of ISCAT/ANTCI NO $x$ flux at SP for BL concentration fall-off of factor of 5. Estimated fluxes are in bold.

\begin{tabular}{|c|c|c|c|c|c|c|}
\hline $\begin{array}{l}\text { Year }^{\mathrm{a}} \\
\text { Time-period }\end{array}$ & $\begin{array}{l}10 \mathrm{~m}-\mathrm{NO}_{x}{ }^{\mathrm{b}} \\
\text { molec cm }^{-3}\end{array}$ & $\begin{array}{r}\text { Avg- } \mathrm{NO}_{x}{ }^{\mathrm{c}} \\
\text { molec cm }^{-3}\end{array}$ & $\begin{array}{r}\mathrm{BLD}_{\text {avg }}{ }^{\mathrm{d}} \\
\mathrm{cm}\end{array}$ & $\begin{array}{l}\mathrm{NO}_{x} C D_{f 5}{ }^{\mathrm{e}} \\
\operatorname{molec~cm}^{-2}\end{array}$ & $\tau_{\mathrm{NO}_{x}}^{\mathrm{f}}$ & $\begin{array}{r}\text { Estimated } \mathrm{NO}_{x} \text { Flux } \\
\text { molec } \mathrm{cm}^{-2} \mathrm{~s}^{-1}\end{array}$ \\
\hline $\begin{array}{l}2006 \\
15.11-31.12\end{array}$ & $6.8 \times 10^{9}$ & $4.7 \times 10^{9}$ & $6.1 \times 10^{3}$ & $2.9 \times 10^{13}$ & $3.2 \times 10^{4}$ & $9.06 \times 10^{8}$ \\
\hline $\begin{array}{l}2003 \\
22.11-27.12\end{array}$ & $10 \times 10^{9}$ & $6.5 \times 10^{9}$ & $8.1 \times 10^{3}$ & $5.2 \times 10^{13}$ & $3.8 \times 10^{4}$ & $1.37 \times 10^{9}$ \\
\hline $\begin{array}{l}2000 \\
15.11-31.12\end{array}$ & $3.2 \times 10^{9}$ & $2.1 \times 10^{9}$ & $8.3 \times 10^{3}$ & $1.7 \times 10^{13}$ & $2.7 \times 10^{4}$ & $6.30 \times 10^{8}$ \\
\hline $\begin{array}{l}1998 \\
1.12-31.12\end{array}$ & $7.8 \times 10^{9}$ & $5.4 \times 10^{9}$ & $7.5 \times 10^{3}$ & $4 \times 10^{13}$ & $3.2 \times 10^{4}$ & $1.25 \times 10^{9}$ \\
\hline
\end{tabular}

a Year of $\mathrm{NO}$ or $\mathrm{NO}_{x}$ measurement and time period (Year-time period

b Average $\mathrm{NO}_{x}$ or $\mathrm{NO}$ measured at $10 \mathrm{~m} \mathrm{NO}$ converted to $\mathrm{NO}_{x}$ as discussed in text

c Average $\mathrm{NO}_{x}$ concentration within BLD

$\mathrm{d}$ Average BLD

e Average $\mathrm{NO}_{x}$ column density, given BL concentration fall-off factor of 5

${ }^{\mathrm{f}}$ Average $\mathrm{NO}_{x}$ lifetime

$\mathrm{g}$ Estimated $\mathrm{NO}_{x}$ flux - derived from average column density divided by the average $\mathrm{NO}_{x}$ lifetime.

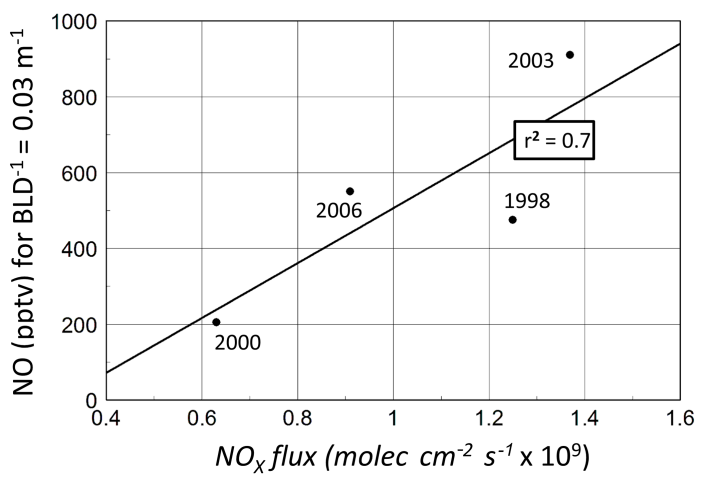

Figure 12. $\mathrm{NO}(\mathrm{BLD}=33.3 \mathrm{~m})$ vs. seasonally averaged $\mathrm{NO}_{x}$ flux from Table 2 using a fall-off factor of 5 (typical of shallow boundary layers).

2013). These larger values also exhibit a larger range of temporal variability due to the diurnal cycle at Dome C.

The range of seasonal flux values and daily variability is smaller than might be expected based on Fig. 11, but it is important to note that under shallow BL conditions, nonlinear growth in $\mathrm{NO}_{x}$ abundance can occur as radical concentrations become suppressed and $\mathrm{NO}_{x}$ lifetime increases (Davis et al., 2004b). Nevertheless, the differences between years are significant and point to other potential factors affecting the seasonal $\mathrm{NO}_{x}$ emission flux. One factor that has already been discussed at some length is the interannual difference in the breakup of the polar stratospheric vortex and associated ozone hole. With regard to nitrate photolysis, this is particularly important to determining the available UV actinic flux in the early austral spring over the Antarctic plateau. As shown in Fig. 1, this breakup happened much earlier in 2000, the year with the smallest seasonal flux. A second related factor has to do with the potential for recycling of $\mathrm{NO}_{x}$ between the firn and atmosphere. As described in the following paragraph, secondary $\mathrm{NO}_{x}$ emissions due to recycling are likely to grow in importance throughout the season and are likely influenced by primary emissions in the early spring.

The $\mathrm{NO}_{x}$ emissions flux represents contributions from both the primary and secondary release of nitrogen from the snow. Primary release represents the photolysis and ventilation of $\mathrm{NO}_{x}$ from nitrate initially deposited through snowfall. This nitrate can be much harder to release due to cage effects (Noyes, 1956) associated with incorporation into the bulk ice phase. By contrast, secondary release of redeposited nitrate should recycle through the atmosphere much faster due to several factors. First, the redeposited nitrate is at the snow surface where higher actinic fluxes are available. Second, being adsorbed to the surface of ice crystals, redeposited nitrate should be more easily photolyzed. In a laboratory experiment by Marcotte et al. (2015), photolysis of nitrate on the ice surface was enhanced by a factor of 3 over nitrate in the bulk ice phase. Finally, redeposition of reactive nitrogen is in the form of both nitric and pernitric acid (Slusher et al., 2002). Pernitric acid would be even more readily photolyzed than nitric acid and its relative importance would also increase at lower temperatures. These arguments may also suggest an explanation for the large year-to-year differences in NO levels, namely differences in snow fall/depth each year. For example, as noted earlier November 2003 had a decrease in snow depth of $1 \mathrm{~cm}$ (and largest NO), whereas November of 2000 had the largest increase of $4 \mathrm{~cm}$ (and lowest NO). While representing these effects with any realism is beyond the scope of this analysis, more detailed modeling and representation of the factors influencing $\mathrm{NO}_{x}$ emissions are being investigated by other groups such as Bock et al. (2016) and Frey et al. (2015). Future laboratory and field studies are needed to further illustrate the complex mechanisms controlling snow $\mathrm{NO}_{x}$ emissions and the chemistry above the snow surface. 


\section{Conclusions}

Earlier work (Davis et al., 2008; Neff et al., 2008), primarily based on 2003 data which included direct sodar measurements of boundary layer depth, presented a straightforward conceptual model that linked high NO to shallow boundary layers, light winds, and stronger surface inversions. In our examination of four seasons of observations, explanation of the initiation and evolution of high NO episodes as well as intra-seasonal to interannual variability proved more challenging. Using four spring-to-summer seasons of observations, we have described the influence of the synoptic-scale to mesoscale weather patterns and their seasonal cycle on stable boundary layer characteristics at the South Pole (SP) in the spring-summer period that set the stage for high NO episodes. These included

1. The relative unimportance of katabatic forcing compared to the accelerations due to synoptic- and mesoscale-scale pressure gradients from November through January. In fact, visualizations of near-surface airflow using ERA-I (Dee et al., 2011) revealed complex mesoscale circulations that belied any simple explanation of accumulation pathways for NO.

2. The effect of clearing skies locally that led to rapid radiative losses and the formation of very shallow inversion/boundary layers and high NO. Given observations only at the SP, the geographical extent of such radiatively driven boundary layers is unknown but worthy of further field observations similar to those reported in Slusher et al. (2010) where aircraft profiling of NO through the boundary layer (above $15 \mathrm{~m}$ ) showed large changes in NO concentrations across the plateau. Unfortunately aircraft measurements of NO in 2003 (Davis et al., 2008) were not permitted between $-20^{\circ} \mathrm{W}$ and $120^{\circ} \mathrm{E}$ (the clean air sector). However, the one flight along $120^{\circ} \mathrm{E}$ showed $\mathrm{NO}$ in excess of $400 \mathrm{pptv}$ between 100 and $400 \mathrm{~km}$ from the SP at the same time as NO concentrations were dropping at the SP.

3. The three-phase transition in spring for $300 \mathrm{hPa}$ winds over the SP. These three phases corresponded to (a) a late winter regime of moisture transport over West Antarctica to the interior when the circumpolar trough is at its maximum and opens the possibility for the transport of NO precursors from northerly latitudes; (b) a semi-bimodal regime with $300 \mathrm{hPa}$ winds alternating between northwest and southeast quadrants, during November and early December, as part of the seasonal cycle; followed by (c) a summer regime favoring $300 \mathrm{hPa}$ winds from the Weddell Sea and warmer cloudy conditions. During the second phase, $300 \mathrm{hPa}$ winds from the southeast favored clear skies, light surface winds and shallow inversions conducive to high NO concentrations at the same time the total column ozone was still low allowing higher actinic fluxes. $300 \mathrm{hPa}$ winds from the northwest favored warm-air advection and cloudy conditions resulting in deep boundary layers and low NO concentrations.

Because of the importance of southeast winds aloft to high NO episodes we examined the frequency of their occurrence at $300 \mathrm{hPa}$ as well as winds at the surface from the east to south during late spring (Days 310-340) from 1961 to 2013 and found strong interannual variability. At $300 \mathrm{hPa}$ the interannual variance was significant but modulated on decadal timescales with a maximum in the period 1995-2010. At the surface, the interannual variance doubled with an upward trend of $30 \%$ in the mean in the last 30 years. We also found that extremes in the frequency of occurrence of southeast winds at $300 \mathrm{hPa}$ correlated well with extremes in easterly surface winds at the surface $\left(r^{2}=0.4\right)$. This suggests that continuous multi-year monitoring may be advisable to avoid sampling bias in the interpretation of the chemical environment over the high Antarctic plateau. We also examined wind distributions aloft between the periods 1961-1980 and 19902010 and found no systematic change except that related to the weakening of the tropopause and increased coupling of winds between 300 and $200 \mathrm{hPa}$. We concluded that the delay in the breakup of the ozone hole in recent decades has allowed higher actinic fluxes to coincide with the optimum time in spring when boundary layer conditions are conducive to high NO concentrations.

We also examined NO data collected in 2006 confirming the systematic relationship between NO concentrations and wind direction shifts to easterly with lower temperatures, lower wind speeds, and shallow boundary layers. In comparing 2006-2007 with other years, we found similar frequencies of easterly surface winds in 2003, fewer in 1998, and the least in 2000. We carried out a case study from 2006 that occurred just prior to the final stratospheric warming. It was at this time that a minimum in cloudiness occurred; a minimum that is persistent in the long-term climatology over 50 years although subject to some synoptic "noise." Over a few hours in this case study, winds aloft rotated $180^{\circ}$ from northerly to southerly (in a grid sense), a mesoscale cool front moved from the northeast (observed in two AWS stations $100 \mathrm{~km}$ from the Pole and captured by ERA-I reanalysis) and skies cleared. With a clearing sky, a surface inversion formed below $10 \mathrm{~m}$ and $\mathrm{NO}$ climbed in $10 \mathrm{~min}$ averages of up to $1200 \mathrm{pptv}$ with light surface winds from the southeast. NO $>400$ pptv lasted only eight hours in this case with sustained moderate NO (150-400 pptv) lasting for another $48 \mathrm{~h}$ in a sustained northeasterly flow (see Fig. 8). This case also reveals the difficulty in correlating peaks in NO directly with upper-level winds insofar as the peak in NO occurs in the gap between rawinsonde observations. Perhaps more important are these transitions in upper-level winds that signify a direct connection to large-scale dynamical changes in the atmosphere over the plateau. 
We argued that the source area for extreme NO concentrations may have been a shallow basin that extended about $100 \mathrm{~km}$ from the South Pole to the southeast. In this case we hypothesize that the short-term peak in NO occurred, not from transport in a long-range katabatic circulation but rather originated from local, subtle terrain accumulation areas in the vicinity of the SP. This was coupled with rapid radiative losses from the snow surface that created a strong surface inversion below $10 \mathrm{~m}$. In some respects, this situation is similar to the peaks in NO that occur at more northerly sites such as Concordia Station where an evening peak in NO occurs with the collapse of the daytime convective boundary layer into a shallow stable boundary layer. In such cases long fetches are not necessary to achieve extremes in the concentrations of NO. However, in 2006, only $15 \%$ of the hourly NO data exceeded 400 pptv, whereas $53 \%$ lay between 100 and 200 pptv. It is in this latter range that accumulation in long fetches associated with stable boundary layers and mesoscale and synoptic-scale circulations may be most relevant. However, without observations further away for the SP, we can not rule out the possibility that high NO is first generated in a larger area of light winds and shallow boundary layers upwind of the SP and then with increases in wind speed and boundary layer depth undergoes dilution. Furthermore with the observations available, we cannot rule out mesoscale convergence of boundary layer air rich in NO that would lead to deeper boundary layers with higher NO. In addition, further away from the SP where convective mixing is possible during part of the diurnal cycle, further dilution is also possible along longer fetches. These results suggest further studies of chemical and boundary layer processes along pathways more complicated than predicted by katabatic flow arguments, particularly with the subtle topography to the east and southeast of the SP.
We developed a method to estimate boundary layer depth using $20 \mathrm{~m}$ meteorological tower data together with direct depth measurements in 2003 and tested against an independent data set collected in 1993. Step-wise linear regression using wind speed and direction, temperature, and the 2-20 m tower temperature difference produced regression equations that accounted for about $70 \%$ of the variance with direct observations. These equations were applied to all four seasons of NO data and confirmed the inverse depth relationships found in earlier studies. However, we also found significant year-to-year differences in magnitude of these inverse relationships that suggested interannual variability in the surface fluxes of NO. To calculate $\mathrm{NO}_{x}$ fluxes, the BLD data were used to obtain an estimate of the $\mathrm{BL}$ column $\mathrm{NO}_{x}$ abundance (based on 2006 data where $\mathrm{NO} / \mathrm{NO}_{x} \sim 0.7$ ). The abundance was derived from surface $\mathrm{NO}$ observations using a range of fall-off values of with height obtained from tethersonde profiles in 2003 and calculated using the increased lifetime of $\mathrm{NO}_{x}$ for very shallow boundary layers. For each season, we found the average NO (scaled at $33.3 \mathrm{~m}$ from a least-squares fitting of NO vs. BLD $^{-1}$ for each of four seasons) which followed a nearly linear relationship with the seasonally averaged fluxes of $\mathrm{NO}_{x}$ confirming the consistency of our analysis. The source of the year-to-year variability in fluxes was not resolved but the variability was consistent with similar results at Concordia Station.

Data availability. The sources of routine meteorological data are cited in the text. The NO and direct sodar boundary layer depth measurement data can be found in the Supplement. 


\section{Appendix A: Boundary layer depth estimation}

In the main sections of the paper we discussed the large- and meso-scale influences on local micrometeorology and chemistry that can set the stage for enhanced levels of NO. Past work has implicated shallow boundary layers as a key ingredient in high NO episodes (Davis et al., 2004b). These shallow boundary layers were associated with lower wind speed, changes in wind direction, colder temperatures, and greater static stability as indicated by the temperature difference between 2 and $22 \mathrm{~m}$ on a nearby tower (Fig. 4). Although a shallow BLD was proposed as a major factor underlying high-NO episodes, the only direct BLD measurements were those carried out in 2003 using a sodar in combination with surface turbulence measurements and balloon profiling (Neff et al., 2008). However, such supporting measurements were not available for other field seasons.

With this background, we examined regression analysis of NO and BLD against the various meteorological variables available to us for all four field seasons including the more recent data from 2006. This establishes some of the basic relationships between NO and BLD for the routine meteorological variables. However, owing to potential collinearity between a number of the variables, we also pursued stepwise linear regression to find a subset of the variables that best account for NO and BLD for each observational period. This approach eliminates redundant variables and identifies a simple subset of variables to develop prediction equations for BLD through multiple linear regression (MLR). Establishing a relationship between $\mathrm{NO}$ and BLD, it then becomes possible to explore the unique chemical mechanisms which might be responsible for the high concentrations of $\mathrm{NO}$ at SP as compared with other sites and with the heretofore under prediction by chemical models (Davis et al., 2008; Frey et al., 2015).

The most routine hourly variables available at SP include wind speed (WS) and direction (WD), temperature ( $T$ ), and temperature difference across a $20 \mathrm{~m}$ tower $(\Delta T)$. We also considered hourly direct solar irradiance (DR), net longwave irradiance NIR, and solar zenith angle (SZA). (The variables DR, NIR, and SZA were available from www.esrl. noaa.gov/gmd.) Cloud fraction (CF) was available as a daily average from station climatological records, whereas bulk stability $\left(\Delta T_{\mathrm{B}}\right)$ was obtained from the twice daily rawinsonde in summer. Sodar data gathered in 1993 (Neff, 1994) provided an additional test data set with which to evaluate the effectiveness of the 2003 MLR results. These data were stored as facsimile records rather than digitally (unlike the 2003 data where automated processing was used; Neff et al., 2008). Also, the sodar in 1993 was operating in a Doppler wind measuring mode, so the pulse resolution was coarser $(\sim 30 \mathrm{~m})$; therefore, echo layers and hence BLD appeared to extend higher by one-half the pulse length or $15 \mathrm{~m}$. To correct for this effect $15 \mathrm{~m}$ was subtracted from the BLD estimates.
Linear regression results are shown in Table A1 for NO in each of the four field seasons along with results for measured BLD given in Table A2 for 2003. In all four years, the dependence of NO on near surface stability $\Delta T$ is consistent. In 2003 and 2006, NO depended primarily on WD, $T$, and $\Delta T$; WS was more important in 2003 than 2006. In Table A2, we show overall regression results for BLD in 2003 as well as a breakdown into two periods corresponding to the dynamical changes around JD 340 (6 December). The early period, JD 326-340, is dominated by WS, $T$, SZA, and net radiation. The change in the impact of bulk temperature difference in this period $\Delta T_{\mathrm{B}}$, from the rawinsonde, marks the change due to the seasonal cycle as in Fig. S4a. However, based on Fig. S4a, katabatic forcing will be small compared to that due to large-scale weather systems. During the later period, JD 340-361, WS, WD, $\Delta T$, and cloud fraction CF play bigger roles.

In general, $\mathrm{NO}$ and $2 \mathrm{~m}$ temperature have robust seasonal trends from October to late November, except in the year 2000 when the polar vortex broke up a month earlier than normal and the temperature showed no trend after early November; and in 2003 when the trend persisted into early December. In 2003, the dependence of NO on SZA is quite clear with moderate dependence on direct solar irradiance whose variability depends to some degree on cloudiness (see Figs. 4 and 10: with respect to Fig. 10a, the simple linear regression between NO and DR in Table A1 does not capture the threshold effect evident in the figure). Cases with low DR in Fig. 10a and low NO usually occur under high wind conditions with deep boundary layers. The dependence of BLD on tower-measured $\Delta T$ is greater than on the bulk inversion temperature difference $\Delta T_{\mathrm{B}}$ which is typically measured over several hundred meters: this is consistent with the fact that the BLD is usually much shallower than the background temperature inversion and more consistent with the $\Delta T$ measured on the $22 \mathrm{~m}$ tower. When $\Delta T$ is dominant over $\Delta T_{\mathrm{B}}$ it indicates that the shallow temperature inversion is likely due to surface radiative cooling (with clearing skies) rather than synoptic weather changes. Comparison of these correlations with those from the more extended data in 1993 sheds some insight into the appropriate variables to use in our MLR analyses (Table 3).

From Table A3 (1993 Data), the dependence of BLD on wind speed increases significantly from October to December while the dependence on $\Delta T$ is remarkably consistent; after October, there is little dependence on either cloud fraction or bulk inversion strength. The increased dependence on WS in December is consistent with changes following the breakup of the polar vortex and the progression of the seasonal cycle. Comparing monthly averaged $\Delta T$ with $\Delta T_{\mathrm{B}}$ yields the following result: October $\left(1.44 / 16.5^{\circ} \mathrm{C}\right)$, November $\left(0.34 / 8.3^{\circ} \mathrm{C}\right)$, and December $\left(0.47 / 0.10^{\circ} \mathrm{C}\right)$. Typical bulk inversion strength was obtained over average depths of 542 , 579 , and $622 \mathrm{~m}$ for each month respectively. This demonstrates the strong seasonal cycle in inversion strength and 
Table A1. Regression $\left(r^{2}\right)$ of meteorological variables with NO. $r^{2}>0.2$ in bold. No trends were removed.

\begin{tabular}{lcccccccr}
\hline & WS & WD & $T$ & $\Delta T$ & CF & $\Delta T_{\mathrm{B}}$ & SZA & DR \\
\hline NO 1998 (JD 335-365) & 0.15 & 0.07 & $\mathbf{0 . 2 6}$ & $\mathbf{0 . 2 6}$ & 0.15 & 0.00 & 0.11 & n/a \\
NO 2000 (JD 320-366) & 0.14 & 0.16 & 0.11 & $\mathbf{0 . 4 1}$ & 0.08 & 0.01 & 0.00 & n/a \\
NO 2003 (JD 326-361) & $\mathbf{0 . 2 9}$ & $\mathbf{0 . 4 5}$ & $\mathbf{0 . 5 1}$ & $\mathbf{0 . 2 5}$ & 0.18 & $\mathbf{0 . 3 4}$ & $\mathbf{0 . 3 7}$ & 0.14 \\
NO 2006 (JD 320-379) & 0.18 & $\mathbf{0 . 2 5}$ & $\mathbf{0 . 5 6}$ & $\mathbf{0 . 3 6}$ & 0.06 & $\mathbf{0 . 3 4}$ & 0.07 & 0.15 \\
\hline
\end{tabular}

Table A2. Linear regression of BLD with observed meteorological variables in 2003. Bolding is the same as in Table A1.

\begin{tabular}{lrrrrrrrrr}
\hline & WS & WD & $T$ & $\Delta T$ & CF & $\Delta T_{\mathrm{B}}$ & SZA & DR & NIR \\
\hline BLD 2003 (JD 326-361) & $\mathbf{0 . 5 6}$ & 0.10 & $\mathbf{0 . 2 5}$ & $\mathbf{0 . 3 2}$ & 0.03 & 0.14 & 0.13 & 0.07 & 0.00 \\
JD 326-340 & $\mathbf{0 . 4 8}$ & 0.01 & $\mathbf{0 . 7 3}$ & 0.15 & $\mathbf{0 . 2 1}$ & $\mathbf{0 . 2 3}$ & $\mathbf{0 . 7 2}$ & 0.02 & $\mathbf{0 . 5 8}$ \\
JD 340-361 & $\mathbf{0 . 6 7}$ & $\mathbf{0 . 4 6}$ & 0.06 & $\mathbf{0 . 5 3}$ & $\mathbf{0 . 3 2}$ & 0.10 & 0.19 & 0.16 & 0.14 \\
\hline
\end{tabular}

Table A3. Regression $\left(r^{2}\right)$ of meteorological variables with BLD, October-December 1993 (no radiation data in 1993). Bolding is the same as in Table A1.

\begin{tabular}{lrrrrrr}
\hline & WS & WD & $T$ & $\Delta T$ & CF & $\Delta T_{\text {B }}$ \\
\hline OCT & $\mathbf{0 . 3 3}$ & 0.07 & $\mathbf{0 . 2 0}$ & $\mathbf{0 . 2 3}$ & 0.02 & 0.17 \\
NOV & $\mathbf{0 . 3 7}$ & $\mathbf{0 . 2 0}$ & 0.02 & $\mathbf{0 . 2 7}$ & 0.06 & 0.00 \\
DEC & $\mathbf{0 . 6 4}$ & 0.01 & 0.15 & $\mathbf{0 . 2 4}$ & 0.01 & 0.00 \\
JD 326-361 & $\mathbf{0 . 6 1}$ & 0.04 & 0.17 & $\mathbf{0 . 2 4}$ & 0.00 & 0.00 \\
\hline
\end{tabular}

the changing seasonal impact on katabatic forcing of surface winds (see Fig. S4a). In December the near-surface (2$22 \mathrm{~m}$ ) inversion is much stronger than the bulk value from the rawinsonde suggesting that any slope effects will reflect nearby terrain variations such as those shown in Fig. 6. It should be noted that the effect of WD on BLD is greatest in the transition month of November. With a weaker inversion strength in the summer, those winds (December) respond mostly to mesoscale and synoptic-scale weather influences such as cloudy vs. clear skies and/or high vs. low wind speeds rather than katabatic forcing.

\section{A1 Linear regression}

Because of the potential covariance of meteorological variables (e.g., often when the wind direction shifts to the southeast, wind speed, $\Delta T$, and temperature all decrease: see Fig. 7), we used stepwise linear regression (using SPSS) of NO and BLD with principal meteorological data as summarized in Table A4. The value of stepwise regression is that it orders the results by magnitude of the importance of variables to the regression. In Table A4, step-wise regression reveals year-to-year variability in important variables depending on the year-to-year variability of dominant meteorological regimes. It should also be noted that the step-wise regression process can produce a different sequence of regression coefficients than those obtained from individual regressions as can be seen in comparing Table A1 and Table A4. The process also excludes variables that are collinear with other variables in the time series. In this case, results with at least an improvement of 0.02 in $r^{2}$ are presented as shaded. For BLD in 2003 the principal predictors are WS (56\%), $T(10 \%$ improvement), and WD (7\% improvement). Including $\Delta T$ adds little $(0.01)$ because it is significantly correlated with both WS and WD $\left(r^{2}=0.3\right.$ for both). When the stepwise regression is applied to only JD 340-361, the ordering is WS, $\mathrm{WD}$, and $\Delta T$ with $T$ being dropped because there is no temperature trend. When examining the results for NO, the yearto-year differences in meteorology can be seen in the dominant independent variable for each year: 1998: WS; 2000: $\Delta T$; 2003: $T$; and 2006: WD. For the most part, meteorology can account for about $50 \%$ of the variance in NO leaving unknowns in the emission source terms unaccounted for. 2003 was an exception with $78 \%$ of the variance for which meteorology provided the explanation for the variability in NO.

Given the dependence of BLD and NO on WS, WD, $T$, and $\Delta T$ for various periods we used these four variables to obtain regression equations for 2003 and 1993 using sodar derived BLD. For testing purposes the regression equation from 2003 was applied to both 2003 and 1993 as well as the regression equation from 1993 to both 1993 and 2003. The equations used were

$$
\text { 2003: } \begin{aligned}
\mathrm{BLD}= & 66.9+18.8 \times \mathrm{WS}+0.23 \\
& \times \mathrm{WD}+2.9 \times T-16.0 \times \Delta T ; \\
1993: \quad \mathrm{BLD}= & 68.3+16.1 \times \mathrm{WS}-0.04 \\
& \times \mathrm{WD}+2.3 \times T-10.0 \times \Delta T .
\end{aligned}
$$

For 2003, $r^{2}=0.74$ with all the variables highly significant at the 0.000 level (using SPSS software); for 1993, $r^{2}=0.64$ with all the variables, except WD, significant at 0.000 (WD was at 0.080 ). Shifting the time series 10 days earlier made 
(a)

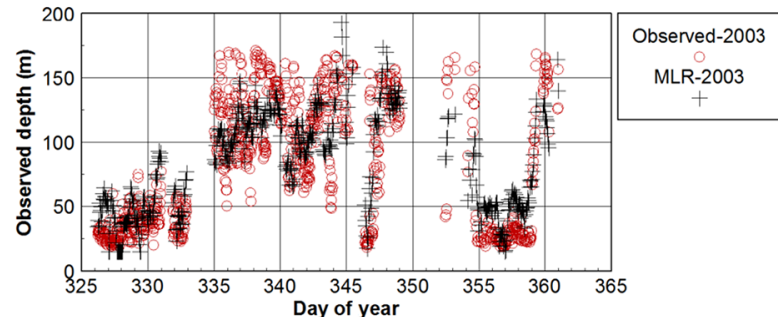

(b)

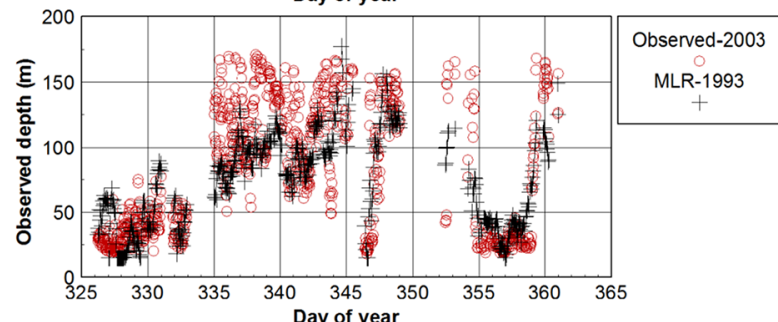

(c)

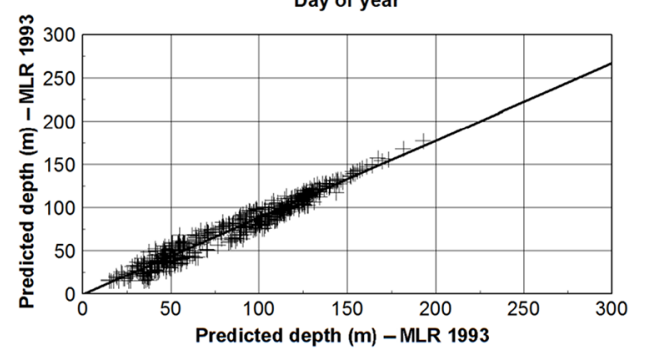

(d)

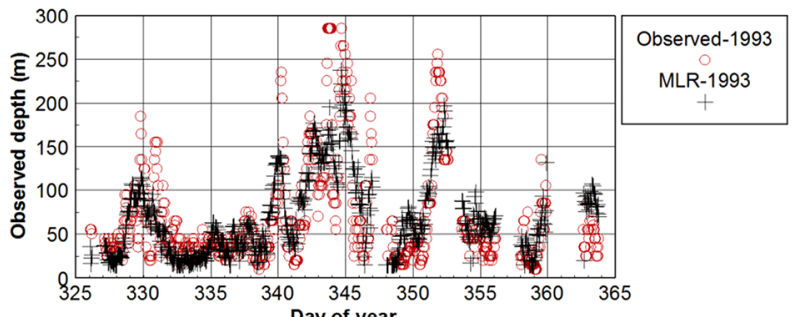

(e)

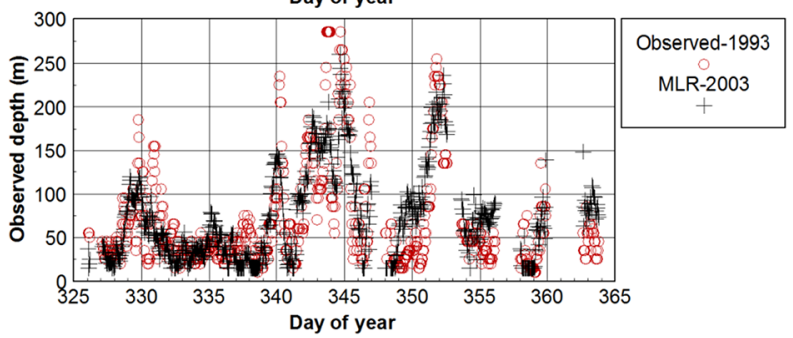

(f)

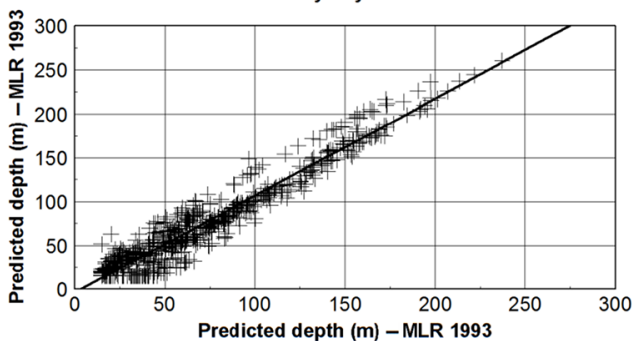

Figure A1. (a) Comparison of 2003 observed BLD with that predicted by the 2003 MLR equation with $r^{2}=0.71$. (b) Comparison of 2003 observed BLD with that predicted by the 1993 MLR equation with $r^{2}=0.67$. (c) Least-squares fit for MLR1993 vs. MLR 2003 with $r^{2}=0.96$. (d) Comparison of 1993 observed BLD with that predicted by the 1993 MLR equation with $r^{2}=0.65$. (e) Comparison of 1993 observed BLD with that predicted by the 2003 MLR equation with $r^{2}=0.61$. (f) Least-squares fit for MLR2003 vs. MLR 1993 with $r^{2}=0.93$.

Table A4. Stepwise linear regression analysis $\left(r^{2}\right)$ for BLD and NO (mid-November-December). Stepwise improvements of 0.02 or better are highlighted.

\begin{tabular}{llllll}
\hline BLD & 2003 (all) & 0.56 & $\mathbf{0 . 6 6}$ & $\mathbf{0 . 7 3}$ & 0.74 \\
\hline \multirow{4}{*}{ Variable } & WS & $+T$ & + WD & $+\Delta T$ \\
2003 & $\mathbf{0 . 6 7}$ & $\mathbf{0 . 7 2}$ & $\mathbf{0 . 7 4}$ & Excluded \\
(Days 340-361) & & & & \\
Variable & WS & $+\Delta T$ & + WD & $T$ \\
1993 & $\mathbf{0 . 6 0}$ & $\mathbf{0 . 6 3}$ & 0.64 & Excluded \\
& Variable & WS & $+T$ & $+\Delta T$ & WD \\
\hline NO & 1998 & $\mathbf{0 . 2 5}$ & $\mathbf{0 . 4 0}$ & $\mathbf{0 . 4 3}$ & $\mathbf{0 . 4 7}$ \\
\hline \multirow{4}{*}{ Variable } & WS & $+\Delta T$ & $+T$ & + WD \\
& 2000 & $\mathbf{0 . 4 2}$ & $\mathbf{0 . 5 1}$ & $\mathbf{0 . 5 4}$ & 0.55 \\
Variable & $\Delta T$ & + WS & $+T$ & + WD \\
2003 & $\mathbf{0 . 5 1}$ & $\mathbf{0 . 7 6}$ & $\mathbf{0 . 7 8}$ & 0.79 \\
Variable & T & + WD & + WS & $+\Delta T$ \\
2006 & $\mathbf{0 . 3 2}$ & $\mathbf{0 . 4 8}$ & $\mathbf{0 . 5 3}$ & $\mathbf{0 . 5 9}$ \\
Variable & WD & $+\Delta T$ & $+T$ & + WS \\
\hline
\end{tabular}

all variables highly significant showing the importance of changing weather regimes each year and sensitivity to the length of the time series. The major difference between 2003 and 1993 lies in the relative weights given to WD and $\Delta T$ : in 1993 they are of the same sign (reducing BLD), whereas in 2003 they are opposite in sign and partially cancelling. Figure A1a, b and c show the results of applying the MLR technique (using WS, WD, $\Delta T$, and $T$ ) to 2003 data, while Fig. A1d, e and f show comparisons using 1993 data. As can be seen in the figures the regression equations capture the transitions between shallow and more deeply mixing boundary layers quite nicely. Because the minimum range for the sodar observations was about $15 \mathrm{~m}$, we set all MLR estimated BLD values less than $15 \mathrm{~m}$ (some were negative) to that value. For deeper observed BLD in 2003, the MLR for both 2003 and 1993 regression equations underestimate the depth; for shallow BLD, the MLR overestimates the depth. Overall the MLR method captures about $70 \%$ of the variance for both 2003 and 1993. It is also of note that the 2003 MLR, based only on observations to $160 \mathrm{~m}$, does capture the deeper observed BLD in 1993 (Fig. A1), suggesting that wind speed dominates the regression fit in those cases. Figure A1c provides a scatterplot for 2003 data using 1993 and 
2003 regression fits with $r^{2}=0.96$. For 1993 data (Fig. A1f), the scatterplot appears to show two modes perhaps because of a weather regime shift not captured by the MLR method using just a few meteorological variables (e.g., there was a major change in bulk inversion strength $\Delta T_{\mathrm{B}}$ around midDecember). In this case the two equations still agree quite well with $r^{2}=0.93$.

\section{A2 Results}

We have extended the past analysis of boundary-layer depth (BLD) effects on NO concentrations from data collected at SP in 2003 to new data collected in 2006-2007 as well as past field programs carried out in 1998 and 2000-2001. Stepwise linear regression showed that the principal variables affecting both NO and BLD were wind speed and direction, temperature, and low-level static stability as measured on a $22 \mathrm{~m}$ tower. We then used these variables to develop a multiple linear regression equation for BLD using sodar data from 2003 and simple meteorological tower measurements. When we tested the regression equation derived from 2003 data against independent sodar data collected in 1993, we accounted for $60-70 \%$ of the variance in estimating BLD. We then applied these equations to each year of NO data to examine the NO response to BLD. When the data were binned in $100 \mathrm{pptv}$ bins (Fig. 11), we found a linear fit between NO and 1/BLD with regression fits accounting for 88 to $97 \%$ of the variance confirming past results. When we looked at the binned data for $\mathrm{BLD}=100 \mathrm{~m}$, all four years converged with NO levels of about $50-100$ pptv. However, at BLD $=25 \mathrm{~m}$ there was a systematic spread in $\mathrm{NO}$ according to observation year resulting in NO that ranged from 200 to 1000 pptv. In looking at the results of step-wise linear regression for $\mathrm{NO}$ we found a different primary variable in the regression for each year: 1998: WS; 2000: $\Delta T$; 2003: $T$; and 2006: WD. This primarily reflects the different weather regimes for each year and the need for multi-year observations to fully understand the various factors leading to high NO concentrations. 


\section{The Supplement related to this article is available online at https://doi.org/10.5194/acp-18-3755-2018-supplement.}

Competing interests. The authors declare that they have no conflict of interest.

Acknowledgements. NOAA/ESRL Global Monitoring Division (GMD) personnel were responsible for SP data collection during the year 2006 starting on 5 February 2006 through 15 January 2007. GMD also maintained the data base for the $22 \mathrm{~m}$ tower, Dobson ozone and radiation measurements at the SP (https://www.esrl.noaa.gov/gmd/dv/ftpdata.html). The Antarctic Meteorological Research Center data bases (AMRC, ftp://amrc.ssec.wisc.edu/pub/southpole/) provided rawinsonde, AWS, and climatological data. NSF's Office of Polar Programs grants OPP-9725465 and OPP-0230246 (PI, Douglas Davis) provided partial funding for the ISCAT and ANTCI projects. The sodar data obtained in 1993 were supported by NSF grant OPP 91-1896 (PI, William Neff). We are also indebted to one of the anonymous reviewers for their very thorough reading of the manuscript.

Edited by: Anna Jones

Reviewed by: two anonymous referees

\section{References}

Arimoto, R., Zeng, T., Davis, D., Wang, Y., Khaing, H., Nesbit, C., and Huey, G.: Concentrations and sources of aerosol ions and trace elements during ANTCI-2003, Atmos. Environ., 42, 2864 2876, 2008.

Ball, F. K.: Winds on the Ice Slopes of Antarctica, Antarctic Meteorology, Proceedings of the Symposium in Melbourne, February 1959, Melbourne, Australia, Pergamon Press, 9-16, 1960.

Berhanu, T. A., Savarino, J., Erbland, J., Vicars, W. C., Preunkert, S., Martins, J. F., and Johnson, M. S.: Isotopic effects of nitrate photochemistry in snow: a field study at Dome C, Antarctica, Atmos. Chem. Phys., 15, 11243-11256, https://doi.org/10.5194/acp-15-11243-2015, 2015.

Black, R. X. and McDaniel, B. A.: Interannual variability in the Southern Hemisphere circulation organized by stratospheric final warming events, J. Atmos. Sci., 64, 2968-2974, 2007.

Bock, J., Savarino, J., and Picard, G.: Air-snow exchange of nitrate: a modelling approach to investigate physicochemical processes in surface snow at Dome C, Antarctica, Atmos. Chem. Phys., 16, 12531-12550, https://doi.org/10.5194/acp-16-125312016, 2016.

Bonner, C. S.: High resolution remote sensing of the atmospheric boundary layer over Antarctica, $\mathrm{PhD}$, physics, University of New South Wales, New South Wales, Australia, 105 pp., 2015.

Bonner, C. S., Ashley, M. C. B., Cui, X., Feng, L., Gong, X., Lawrence, J. S., Luong-Van, D. M., Shang, Z., Storey, J. W. V., Wang, L., Yang, H., Yang, J., Zhou, X., and Zhu, Z.: Thickness of the Atmospheric Boundary Layer Above Dome A, Antarctica, during 2009, Publ. Astron. Soc. Pac., 122, 1122-1131, 2010.
Castellani, B. B., Shupe, M. D., Hudak, D. R., and Sheppard, B. E.: The annual cycle of snowfall at Summit, Greenland, J. Geophys. Res.-Atmos., 120, 6654-6668, 2015.

Charlton, A. J., O’Neill, A., Lahoz, W. A., Massacand, A. C., and Berrisford, P.: The impact of the stratosphere on the troposphere during the Southern Hemisphere stratospheric sudden warming, September 2002, Q. J. Roy. Meteor. Soc., 131, 2171-2188, 2005.

Chen, G., Davis, D., Crawford, J., Nowak, J. B., Eisele, F., Mauldin, R. L., Tanner, D., Buhr, M., Shetter, R., Lefer, B., Arimoto, R., Hogan, A., and Blake, D.: An investigation of South Pole $\mathrm{HO}_{x}$ chemistry: comparison of model results with ISCAT observations, Geophys. Res. Lett., 28, 3633-3636, 2001.

Chen, G., Davis, D., Crawford, J., Hutterli, L. M., Huey, L. G., Slusher, D., Mauldin, L., Eisele, F., Tanner, D., Dibb, J., Buhr, M., McConnell, J., Lefer, B., Shetter, R., Blake, D., Song, C. H., Lombardi, K., and Arnoldy, J.: A reassessment of $\mathrm{HO}_{x}$ South Pole chemistry based on observations recorded during ISCAT 2000, Atmos. Environ., 38, 5451-5461, 2004.

Davis, D., Nowak, J. B., Chen, G., Buhr, M., Arimoto, R., Hogan, A., Eisele, F., Mauldin, L., Tanner, D., Shetter, R., Lefer, B., and McMurry, P.: Unexpected high levels of NO observed at South Pole, Geophys. Res. Lett., 28, 3625-3628, 2001.

Davis, D. D., Eisele, F., Chen, G., Crawford, J., Huey, G., Tanner, D., Slusher, D., Mauldin, L., Oncley, S., Lenschow, D., Semmer, S., Shetter, R., Lefer, B., Arimoto, R., Hogan, A., Grube, P., Lazzara, M., Bandy, A., Thornton, D., Berresheim, H., Bingemer, H., Hutterli, M., McConnell, J., Bales, R., Dibb, J., Buhr, M., Park, J., McMurry, P., Swanson, A., Meinardi, S., and Blake, D.: An overview of ISCAT 2000, Atmos. Environ., 38, 5363-5373, 2004a.

Davis, D., Chen, G., Buhr, M., Crawford, J., Lenschow, D., Lefer, B., Shetter, R., Eisele, F., Mauldin, L., and Hogan, A.: South Pole $\mathrm{NO}_{x}$ chemistry: an assessment of factors controlling variability and absolute levels, Atmos. Environ., 38, 5375-5388, 2004b.

Davis, D. D., Seelig, J., Huey, G., Crawford, J., Chen, G., Wang, Y. H., Buhr, M., Helmig, D., Neff, W., Blake, D., Arimoto, R., and Eisele, F.: A reassessment of Antarctic plateau reactive nitrogen based on ANTCI 2003 airborne and ground based measurements, Atmos. Environ., 42, 2831-2848, 2008.

Davis, D., Neff, W., Crawford, J., Buhr, M., Helmig, D., and Nicovitch, M.: Evidence for rapid photochemical recycling of Antarctic Plateau reactive nitrogen, IPY Oslo Science Conference, 812 June 2010, Oslo, Norway, Abstract EM9.1-3.1, 2010.

Dee, D. P., Uppala, S. M., Simmons, A. J., Berrisford, P., Poli, P., Kobayashi, S., Andrae, U., Balmaseda, M. A., Balsamo, G., Bauer, P., Bechtold, P., Beljaars, A. C. M., van de Berg, L., Bidlot, J., Bormann, N., Delsol, C., Dragani, R., Fuentes, M., Geer, A. J., Haimberger, L., Healy, S. B., Hersbach, H., Holm, E. V., Isaksen, L., Kallberg, P., Kohler, M., Matricardi, M., McNally, A. P., Monge-Sanz, B. M., Morcrette, J. J., Park, B. K., Peubey, C., de Rosnay, P., Tavolato, C., Thepaut, J. N., and Vitart, F.: The ERA-Interim reanalysis: configuration and performance of the data assimilation system, Q. J. Roy. Meteor. Soc., 137, 553-597, 2011.

Eisele, F., Davis, D. D., Helmig, D., Oltmans, S. J., Neff, W., Huey, G., Tanner, D., Chen, G., Crawford, J., Arimoto, R., Buhr, M., Mauldin, L., Hutterli, M., Dibb, J., Blake, D., Brooks, S. B., Johnson, B., Roberts, J. M., Wang, Y. H., Tan, D., and Flocke, F.: Antarctic Tropospheric Chemistry Investiga- 
tion (ANTCI) 2003 overview, Atmos. Environ., 42, 2749-2761, https://doi.org/10.1016/j.atmosenv.2007.04.013, 2008.

Frey, M. M., Brough, N., France, J. L., Anderson, P. S., Traulle, O., King, M. D., Jones, A. E., Wolff, E. W., and Savarino, J.: The diurnal variability of atmospheric nitrogen oxides (NO and $\mathrm{NO}_{2}$ ) above the Antarctic Plateau driven by atmospheric stability and snow emissions, Atmos. Chem. Phys., 13, 3045-3062, https://doi.org/10.5194/acp-13-3045-2013, 2013.

Frey, M. M., Roscoe, H. K., Kukui, A., Savarino, J., France, J. L., King, M. D., Legrand, M., and Preunkert, S.: Atmospheric nitrogen oxides ( $\mathrm{NO}$ and $\mathrm{NO}_{2}$ ) at Dome $\mathrm{C}$, East Antarctica, during the OPALE campaign, Atmos. Chem. Phys., 15, 7859-7875, https://doi.org/10.5194/acp-15-7859-2015, 2015.

Harnik, N., Perlwitz, J., and Shaw, T. A.: Observed decadal changes in downward wave coupling between the stratosphere and troposphere in the Southern Hemisphere, J. Climate, 24, 4558-4569, 2011.

Helmig, D., Johnson, B. J., Warshawsky, M., Morse, T., Neff, W. D., Eisele, F., and Davis, D. D.: Nitric oxide in the boundary-layer at South Pole during the Antarctic Tropospheric Chemistry Investigation (ANTCI), Atmos. Environ., 42, 2817-2830, 2008.

King, J. C., Argentini, S. A., and Anderson, P. S.: Contrasts between the summertime surface energy balance and boundary layer structure at Dome $\mathrm{C}$ and Halley stations, Antarctica, J. Geophys. Res.-Atmos., 111, D02105, https://doi.org/10.1029/2005jd006130, 2006.

Mahesh, A., Eager, R., Campbell, J. R., and Spinhirne, J. D.: Observations of blowing snow at the South Pole, J. Geophys. Res.-Atmos., 108, 4707, https://doi.org/10.1029/2002JD003327, 2003.

Marcotte, G., Marchand, P., Pronovost, S., Ayotte, P., Laffon, C., and Parent, P.: Surface-enhanced nitrate photolysis on ice, J. Phys. Chem. A, 119, 1996-2005, 2015.

Meehl, G. A.: A reexamination of the mechanism of the semiannual oscillation in the Southern Hemisphere, J. Climate, 4, 911-926, 1991.

Meusinger, C., Berhanu, T. A., Erbland, J., Savarino, J., and Johnson, M. S.: Laboratory study of nitrate photolysis in Antarctic snow. I. Observed quantum yield, domain of photolysis, and secondary chemistry, J. Chem. Phys., 140, 244305, https://doi.org/10.1063/1.4882898, 2014.

Mulvaney, R., Wagenbach, D., and Wolff, E. W.: Postdepositional change in snowpack nitrate from observation of year-round nearsurface snow in coastal Antarctica, J. Geophys. Res.-Atmos., 103, 11021-11031, 1998.

Neff, W. D.: An observational and numerical study of the atmospheric boundary layer overlying the east Antarctic ice sheet, $\mathrm{PhD}$ Astrogeophysics, University of Colorado, Boulder, Colorado, USA, 272 pp., 1980.
Neff, W. D.: Studies of the variability in the troposphere and atmospheric boundary layer over the South Pole: 1993 Experiment design and preliminary results, Ant. Journ. U.S., 28, 302-304, 1994.

Neff, W. D.: Decadal time scale trends and variability in the tropospheric circulation over the South Pole, J. Geophys. Res.-Atmos., 104, 27217-27251, 1999.

Neff, W., Helmig, D., Grachev, A., and Davis, D.: A study of boundary layer behavior associated with high NO concentrations at the South Pole using a minisodar, tethered balloons and sonic anemometer, Atmos. Environ., 42, 2762-2779, 2008.

Noyes, R. M.: Models relating molecular reactivity and diffusion in liquids, J. Am. Chem. Soc., 78, 5486-5490, 1956.

Oncley, S. P., Buhr, M., Lenschow, D. H., Davis, D., and Semmer, S. R.: Observations of summertime NO fluxes and boundary-layer height at the South Pole during ISCAT 2000 using scalar similarity, Atmos. Environ., 38, 5389-5398, 2004.

Parish, T. R. and Cassano, J. J.: The role of katabatic winds on the Antarctic surface wind regime, Mon. Weather Rev., 131, 317333, 2003.

Schnell, R. C., Liu, S. C., Oltmans, S. J., Stone, R. S., Hofmann, D. J., Dutton, E. G., Deshler, T., Sturges, W. T., Harder, J. W., Sewell, S. D., Trainer, M., and Harris, J. M.: Decrease of summer tropospheric ozone concentrations in Antarctica, Nature, 351, 726-729, 1991.

Slusher, D. L., Huey, L. G., Tanner, D. J., Chen, G., Davis, D. D., Buhr, M., Nowak, J. B., Eisele, F. L., Kosciuch, E., Mauldin, R. L., Lefer, B. L., Shetter, R. E., and Dibb, J. E.: Measurements of pernitric acid at the South Pole during ISCAT 2000, Geophys. Res. Lett., 29, 2011, https://doi.org/10.1029/2002GL015703, 2002.

Slusher, D., Neff, W., Kim, S., Huey, L., Wang, Y., Zeng, T., Tanner, D., Blake, D., Beyersdorf, A., and Lefer, B.: Atmospheric chemistry results from the ANTCI 2005 Antarctic plateau airborne study, J. Geophys. Res.-Atmos., 115, D07304, https://doi.org/10.1029/2009JD012605, 2010.

Stone, R. S. and Kahl, J. D.: Variations in boundary layer properties associated with clouds and transient weather disturbances at the South Pole during winter, J. Geophys. Res., 96, 5127-5144, 1991.

Van Dam, B., Helmig, D., Neff, W., and Kramer, L.: Evaluation of boundary layer depth estimates at summit station, Greenland, J. Appl. Meteorol. Clim., 52, 2356-2362, 2013.

Yasunari, T. and Kodama, S.: Intraseasonal variability of katabatic wind over East Antarctica and planetary flow regimes in the Southern Hemisphere, J. Geophys. Res., 98, 13063-13070, 1993. 